University of Wollongong

Research Online

Australian Institute for Innovative Materials -

Papers

Australian Institute for Innovative Materials

$1-1-2018$

Creating fast ion conducting composites via in-situ introduction of titanium as oxygen getter

Wenchao Zhang

University of Wollongong,wz990@uowmail.edu.au

Jianfeng Mao

University of Wollongong, jmao@uow.edu.au

Wei Kong Pang

University of Wollongong, wkpang@uow.edu.au

Xing Wang

ETH Zurich

Zaiping Guo

University of Wollongong, zguo@uow.edu.au

Follow this and additional works at: https://ro.uow.edu.au/aiimpapers

Part of the Engineering Commons, and the Physical Sciences and Mathematics Commons

Research Online is the open access institutional repository for the University of Wollongong. For further information contact the UOW Library: research-pubs@uow.edu.au 


\title{
Creating fast ion conducting composites via in-situ introduction of titanium as oxygen getter
}

\author{
Abstract \\ Metal-ion batteries are promising for large-scale energy storage. Their potential commercialization not \\ only depends on their superior electrochemical performance, but also on the large-scale synthesis cost of \\ electrode materials. In the conventional industrial technology for producing non-oxides, argon protection \\ is required to avoid oxidation, leading to additional costs and extra processing. We demonstrate, without \\ protection gas, that ball milling in air with a small amount of Ti additive can be a cost-effective approach \\ for preparing high-performance alloy anodes. Ti consumes the oxygen, forming TiO $2(<10 \mathrm{~nm})$ in situ \\ with high ionic conductivity, while also preventing oxidation and sustaining the electrical conductivity of \\ carbon. This strategy effectively promotes the rate capability (61\% capacity retention from 60 to $3000 \mathrm{~mA}$ \\ $\mathrm{g}-1$ ) of $\mathrm{SnSb} /$ carbon-nanotube anode (over $204 \%$ better than without Ti additive).

\section{Disciplines} \\ Engineering | Physical Sciences and Mathematics

\section{Publication Details} \\ Zhang, W., Mao, J., Pang, W., Wang, X. \& Guo, Z. (2018). Creating fast ion conducting composites via in- \\ situ introduction of titanium as oxygen getter. Nano Energy, 49 549-554.
}




\section{Creating fast ion conducting composites via in-situ introduction of Titanium as oxygen getter}

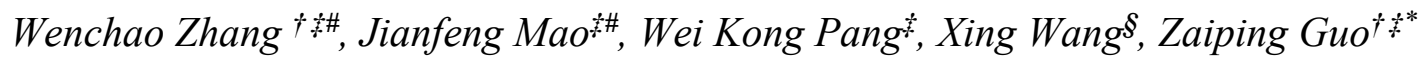

$\dagger$ \$School of Mechanical, Materials, Mechatronics \& Biomedical Engineering, Faculty of Engineering and Information Sciences, University of Wollongong, NSW 2500, Australia.

¥nstitute for Superconducting \& Electronic Materials, University of Wollongong, Wollongong, NSW, 2522, Australia.

\$Institute for Chemical \& Bioengineering, ETH Zurich, Vladimir Prelog Weg 1, 8093 Zurich, Switzerland

*E-mail: zguo@uow.edu.au

\# These authors contributed equally to this work

\section{KEYWORDS}

oxygen getter, ion conductivity, high rate capability, sodium ion batteries 


\begin{abstract}
Metal-ion batteries are promising for large-scale energy storage. Their potential commercialization not only depends on their superior electrochemical performance, but also on the large-scale synthesis cost of electrode materials. In the conventional industrial technology for producing non-oxides, argon protection is required to avoid oxidation, leading to additional costs and extra processing. We demonstrate, without protection gas, that ball milling in air with a small amount of $\mathrm{Ti}$ additive can be a cost-effective approach for preparing high-performance alloy anodes. Ti consumes the oxygen, forming $\mathrm{TiO}_{2}(<10 \mathrm{~nm})$ in situ with high ionic conductivity, while also preventing oxidation and sustaining the electrical conductivity of carbon. This strategy effectively promotes the rate capability $(61 \%$ capacity retention from 60 to $3000 \mathrm{~mA} \mathrm{~g}^{-1}$ ) of SnSb/carbon-nanotube anode (over $204 \%$ better than without Ti additive).
\end{abstract}

\title{
1. Introduction
}

Owing to the rapid developments of electronic devices, electric vehicles, and energy storage systems, low-cost, highly-efficient and large-scale methods of preparing materials for energy storage are urgently needed ${ }^{1,2}$. By offering energy storage with high energy density and long cycle life, lithium- and sodium-ion batteries (LIBs and SIBs) have attracted great attention for the past decades ${ }^{3-10}$. Benefiting from their competitive costs, SIBs have been considered a better candidate than LIBs for grid-scale applications. Among all the currently available electrode materials, alloy-based materials have been proven to be promising anodes for SIBs due to their high gravimetric and volumetric capacities ${ }^{11,12}$. Alloy electrodes undergo enormous volume 
change and continuous pulverization, and therefore show relatively poor cycle performance. Numerous strategies to overcome the degradation of electrodes, such as employing unique nanostructures or introducing a conductive matrix (e.g. carbon) to buffer the volume changes, have been studied in recent years ${ }^{13,14}$. Nevertheless, the effects are hitherto barely satisfactory.

For industrial applications, the synthesis of alloy-based electrodes must be scalable, simple, and low-cost. Various scalable synthesis methods, such as solid-state reaction ${ }^{15}$, electrospinning ${ }^{16}$, glycothermal approach ${ }^{17}$, ball milling ${ }^{18}$, etc., have been studied. Amongst, ball milling is the most appealing large-scale synthesis technique ${ }^{19}$ because of its environmental friendliness (without a solvent involved) and easy operability. In some cases, the preparation of precursors for solid-state synthesis definitely needs the assistance of the ball-milling technique ${ }^{20}$, taking advantages of the ability of ball milling to make small and homogeneous particles. Ball milling requires the protection of argon gas, to avoid unwanted oxidation or other side reactions ${ }^{15}, 19,20$. Undoubtedly, the use of argon gas will not only increase the cost, but also multiply the complexity of operation processes. Inspired by the use of $\mathrm{Ti}$ as an oxygen getter in alloy melting ${ }^{21,22}$ and the excellent ionic conductivity of $\mathrm{TiO}_{2}$ in metal-ion batteries ${ }^{23}$, Ti may be used in the ball milling of alloy electrode materials to form $\mathrm{TiO}_{2}$ as well as protecting the electrode materials from oxidation. Thus, there is a possibility to create an electrode material that combines the merits of a high-capacity alloy-based material with the rapid ion conductivity of $\mathrm{TiO}_{2}$ in a simpler synthesis process. $\mathrm{SnSb}$ is one of the most promising anode materials for SIBs due to its high theoretical capacity $\left(754 \mathrm{~mA} \mathrm{~h} \mathrm{~g}^{-1}\right)$ and stepwise reaction mechanism ${ }^{24}$. Although different strategies have been applied to $\mathrm{SnSb}$ anodes for improving their electrochemical performance in recent years, the long-term cycling performance of $\mathrm{SnSb}$ electrodes at high rates 
has rarely been reported so far, especially for $\mathrm{SnSb}$ fabricated via large-scale synthesis techniques.

Herein, taking $\mathrm{SnSb}$ anode material as an example, we used $\mathrm{Ti}$ as an oxygen getter for the $\mathrm{SnSb}$ fabrication via the ball milling of $\mathrm{Sn}$ and $\mathrm{Sb}$ in air. Without argon protection, this one-step approach will be favourable for the ease of handling and the significantly-reduced synthesis cost. In order to buffer the volume change of $\mathrm{SnSb}$ anode material during cycling in SIBs, untreated commercial multi-wall carbon nanotubes (MWCNTs) were also added to create a conductive buffering matrix. The $\mathrm{TiO}_{2}(<10 \mathrm{~nm})$ with high ionic conductivity and the carbon matrix with good electronic conductivity synergistically improve the high-rate capability $\left(326.9 \mathrm{~mA} \mathrm{~h} \mathrm{~g}^{-1}\right.$ at 3 $\left.\mathrm{A} \mathrm{g}^{-1}\right)$ and cycling stability (63.7\% capacity retention after 300 cycles at $\left.1.2 \mathrm{~A} \mathrm{~g}^{-1}\right)$.

\section{Results and discussions}
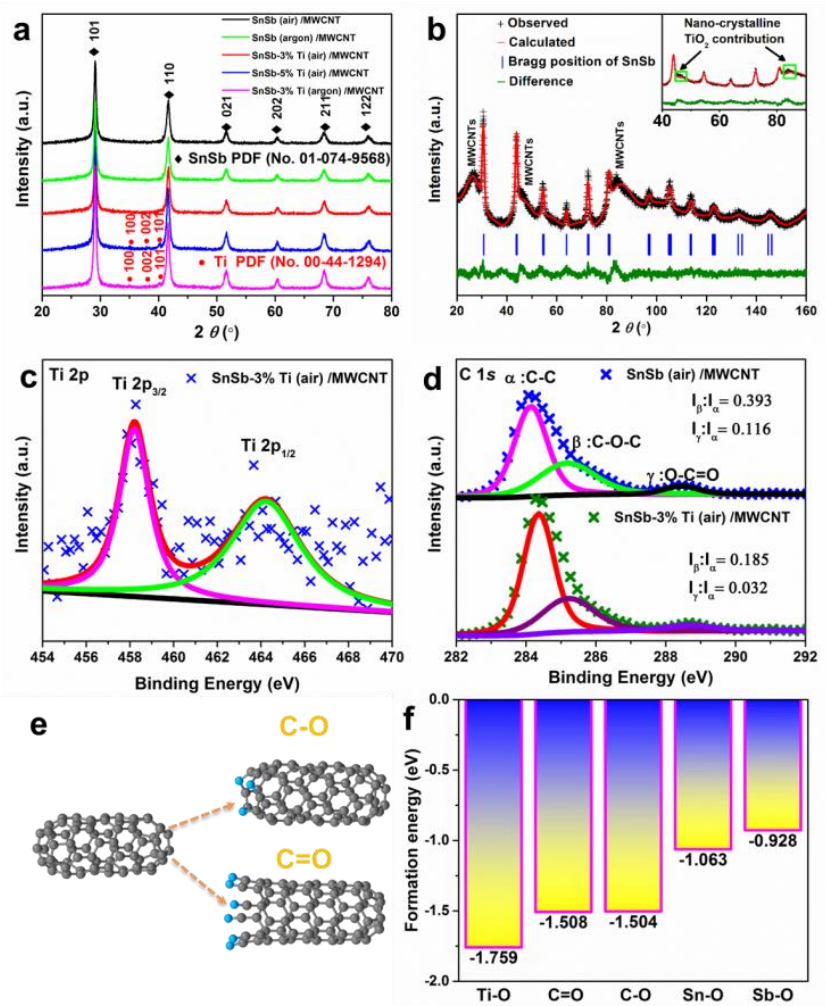
Figure 1 (a) XRD and (b) NPD data (enlargement of unfitted peaks in inset) of the as-prepared powders, (c) the XPS analysis of Ti 2p peak from SnSb-3\% Ti (air) and (d) C 1s peaks from $\mathrm{SnSb}-3 \% \mathrm{Ti}$ (air) and $\mathrm{SnSb}$ (air), (e) edge-model for MWCNT, (f) formation energy of various X-O (X: Ti, C, Sn, Sb) bond per oxygen atom. (SnSb- $x \%$ Ti (air or argon) denotes the SnSb sample containing $x$ wt.\% Ti and 12.5 wt.\% MWCNT prepared in air or argon.)

As depicted in Figure 1a, all the well-defined major peaks in the X-ray diffraction (XRD) patterns can be indexed to the hexagonal $R-3 m \mathrm{SnSb}$ structure. With the addition of $\mathrm{Ti}$, several weak peaks that appear to belong to Ti were observed in the SnSb-5\% Ti (air) and $\mathrm{SnSb}-3 \% \mathrm{Ti}$ (argon), but not in the $\mathrm{SnSb}-3 \% \mathrm{Ti}$ (air). It is possible that most of $\mathrm{Ti}$ in $\mathrm{SnSb}-3 \% \mathrm{Ti}$ (air) was oxidised so that the amount of residual Ti was under the detection limit of XRD. The MWCNT are not observed in XRD, but they can be identified by Raman spectroscopy (Figure S1) and high-resolution neutron powder diffraction (NPD) data (Figure 1b). The Raman spectra clearly show the disordered (D) band and graphitic (G) band of MWCNTs, and the 3 broad peaks at $2 \theta$ $=26,42$, and $84^{\circ}$ in the NPD pattern of the $\mathrm{SnSb}-3 \%$ Ti (air) are due to MWCNTs. Through careful Rietveld analysis of the NPD pattern, the $R-3 m$ SnSb structure was confirmed, as shown in Table S1. There are still unfitted parts, which are highlighted by green rectangles in the inset of Figure 1b. Using the exact same instrumental parameters (from SnSb NPD dataset), a simulated NPD pattern of rutile $\mathrm{TiO}_{2}$ with a particle size of $3 \mathrm{~nm}$, (estimated using transmission electron microscopy (TEM), with details to be shown later) is shown in Figure S2, showing 2 major peaks at the same positions as in the unfitted parts of the NPD spectrum. It is reasonable to believe that those unfitted parts might be due to the contribution of nanocrystalline rutile $\mathrm{TiO}_{2}$. Gibbs free formation energy of oxides (Figure S3) estimated using Thermal-Calc suggests rutile is likely to be formed.

Figure 1c shows the X-ray photoelectron spectroscopy (XPS) spectrum of SnSb-3\% Ti (air) in Ti $2 \mathrm{p}$. The Ti $2 \mathrm{p}_{3 / 2}(458.5 \mathrm{eV})$ and Ti $2 \mathrm{p}_{1 / 2}(464.6 \mathrm{eV})$ peaks can be assigned to the chemical valence of $\mathrm{Ti}^{4+}$, and this observation is consistent with the NPD simulation. XPS spectra for C 
1s, $\mathrm{O} 1 \mathrm{~s}, \mathrm{Sb} 3 \mathrm{~d}$, and $\mathrm{Sn} 3 \mathrm{~d}$ are presented in Figure 1d, Figures S4 and S5, respectively. The Sb $3 d_{5 / 2}(528.3 \mathrm{eV}), \operatorname{Sb} 3 \mathrm{~d}_{3 / 2}(537.7 \mathrm{eV}), \mathrm{Sn} 3 \mathrm{~d}_{5 / 2}(485.2 \mathrm{eV})$, and $\mathrm{Sn} 3 \mathrm{~d}_{3 / 2}(493.6 \mathrm{eV})$ peaks show the metallic nature of Sn and Sb. In all the C 1s XPS spectra, typical C-C (284.8 eV), C-O-C (286 $\mathrm{eV})$, and $\mathrm{O}-\mathrm{C}=\mathrm{O}(288.5 \mathrm{eV})$ peaks were detected. It was found that the ratio of the $\mathrm{C}-\mathrm{O}-\mathrm{C}$ to the C-C peak was 0.185 and 0.393 for the SnSb-3\% Ti (air) and SnSb (air) samples; while the ratio of the $\mathrm{O}-\mathrm{C}=\mathrm{O}$ to the $\mathrm{C}-\mathrm{C}$ peak was 0.032 and 0.116 for the two samples, respectively. It appears that the oxidation of carbon was significantly reduced by Ti, implying Ti works effectively as an oxygen getter that competitively reacts with oxygen during ball milling. Similar results were also observed for other Ti-added samples, such as $\mathrm{SnSb}-5 \% \mathrm{Ti}$ (air) and $\mathrm{SnSb}-3 \% \mathrm{Ti}$ (argon)) (Figure S4a). It was also evident that all the Ti-free samples, including the untreated pure commercial MWCNTs and SnSb (with 12.5 wt. \% MWCNTs), both ball-milled in argon, have higher C-O-C and $\mathrm{O}-\mathrm{C}=\mathrm{O}$ to $\mathrm{C}-\mathrm{C}$ bond ratios than the Ti-containing samples (Figure $\mathrm{S} 4 \mathrm{~b}$ ). The XPS studies above suggest that oxygen preferentially reacts with $\mathrm{Ti}$ and forms $\mathrm{TiO}_{2}$. Density functional theory (DFT) calculations were used to estimate the magnitudes of oxygen affinity for the different elements (Figures 1e and f). $\mathrm{C}-\mathrm{O}$ and $\mathrm{C}=\mathrm{O}$ carbon-oxygen bonds were simulated, and the formation energies of various $\mathrm{X}-\mathrm{O}$ bonds were also calculated for comparison, where $\mathrm{X}$ is $\mathrm{C}$, $\mathrm{Ti}, \mathrm{Sn}$ or $\mathrm{Sb}$. It is clear that Ti-O has the lowest formation energy among all the $\mathrm{X}-\mathrm{O}$ bonds, which agree well with the XPS results. The formation energies of $\mathrm{C}-\mathrm{O}(-1.504 \mathrm{eV})$ and $\mathrm{C}=\mathrm{O}(-$ $1.508 \mathrm{eV})$ bonds are lower than those of Sn-O $(-1.063 \mathrm{eV})$ and $\mathrm{Sb}-\mathrm{O}(-0.928 \mathrm{eV})$, suggesting that MWCNT will be oxidized if there is no Ti present during ball milling, thus reducing its electrical conductivity ${ }^{25}$. 


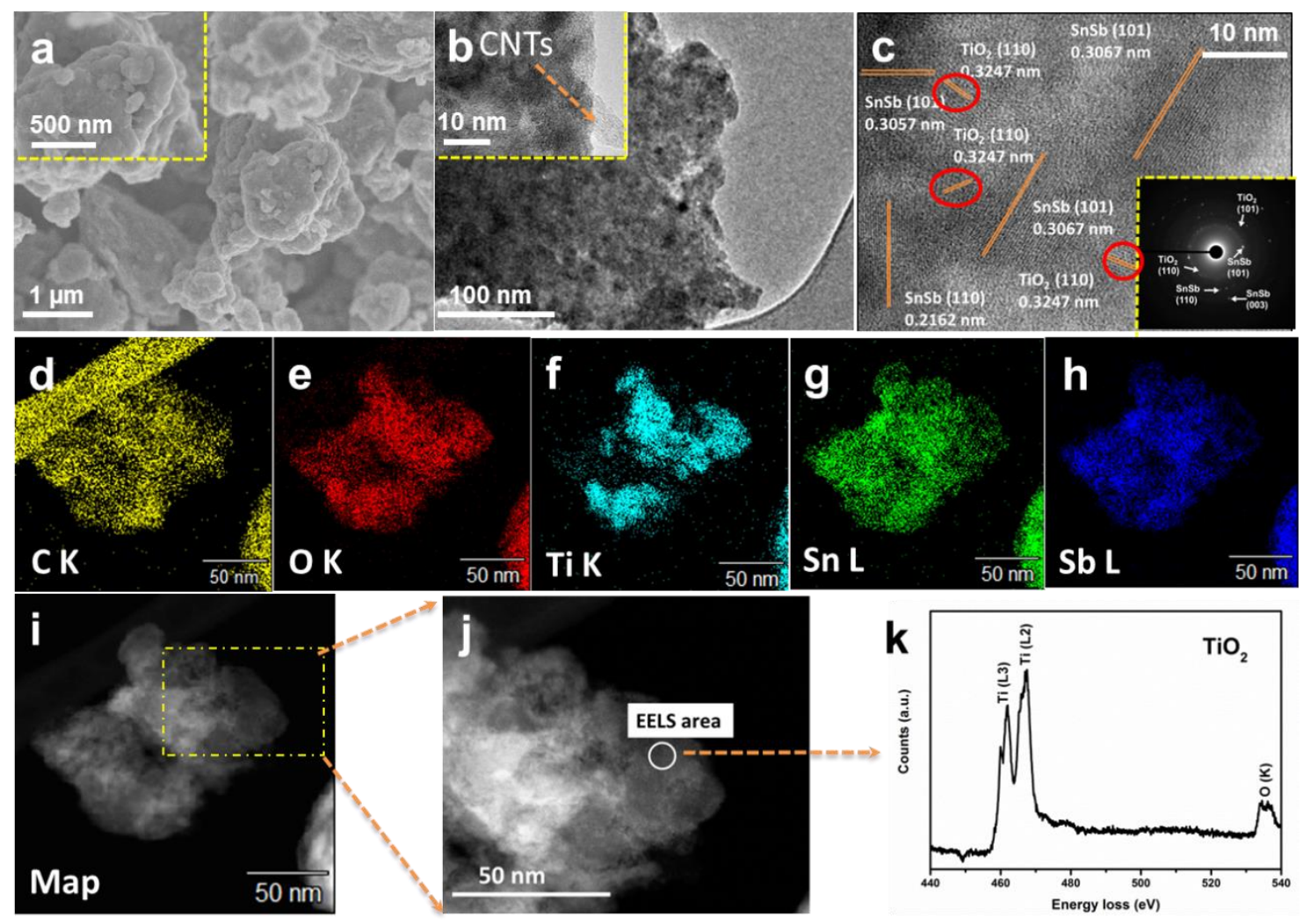

Figure 2 Microscopic characterization of the SnSb-3\% Ti (air) powder. (a) FESEM and (b) TEM images (enlargement in inset), (c) HRTEM image and SAED pattern (inset), with the red outlines indicating the sizes of $\mathrm{TiO}_{2}$ particles, (d-h) STEM mapping, (i-j) STEM images and (k) EELS analysis of the Ti L-edge and O K-edge for the selected area in $(\mathrm{j})$

Figure 2a shows a field-emission scanning electron microscope (FESEM) image showing the morphology of irregular agglomerated micro-sized particles, and Figure $2 \mathrm{~b}$ presents a low magnification TEM image of the SnSb-3\% Ti (air) sample. A high resolution TEM (HRTEM) image and corresponding selected area diffraction (SAED) pattern of the SnSb-3\% Ti (air) powder are given in Figure 2c. The first and faint diffraction ring of the SAED pattern can be indexed as the (110) reflection of $\mathrm{TiO}_{2}$. The second ring with stronger intensity is indexed as the (101) reflection of $\mathrm{SnSb} . \mathrm{TiO}_{2}$ nanoparticles (circled in red) are distributed evenly in the carbon matrix, and their sizes are in the range of 3-6 $\mathrm{nm}$. The lattice fringes of the particles have the 
spacing $\sim 0.3247 \mathrm{~nm}$, which corresponds to the (110) planes of rutile $\mathrm{TiO}_{2}$. It has been reported that ultrafine $\mathrm{TiO}_{2}$ with particle size below $10 \mathrm{~nm}$ could significantly increase capacitive charge storage and enhance the discharge/charge kinetics due to the faradaic reactions on the surfaces of the materials ${ }^{26}$. Figures $2 \mathrm{~d}-\mathrm{k}$ shows X-ray mapping results, scanning TEM (STEM) images, and the electron energy loss spectrum (EELS) of the SnSb-3\% Ti (air) sample. Clearly, the elements $\mathrm{Ti}, \mathrm{Sn}, \mathrm{Sb}, \mathrm{C}$, and $\mathrm{O}$ are distributed uniformly in the composite material. The fine structures near the Ti-L3, Ti-L2, and O-K edges match those of rutile $\mathrm{TiO}_{2}$. The EELS result is consistent with the NPD, SAED, and HRTEM results given earlier.
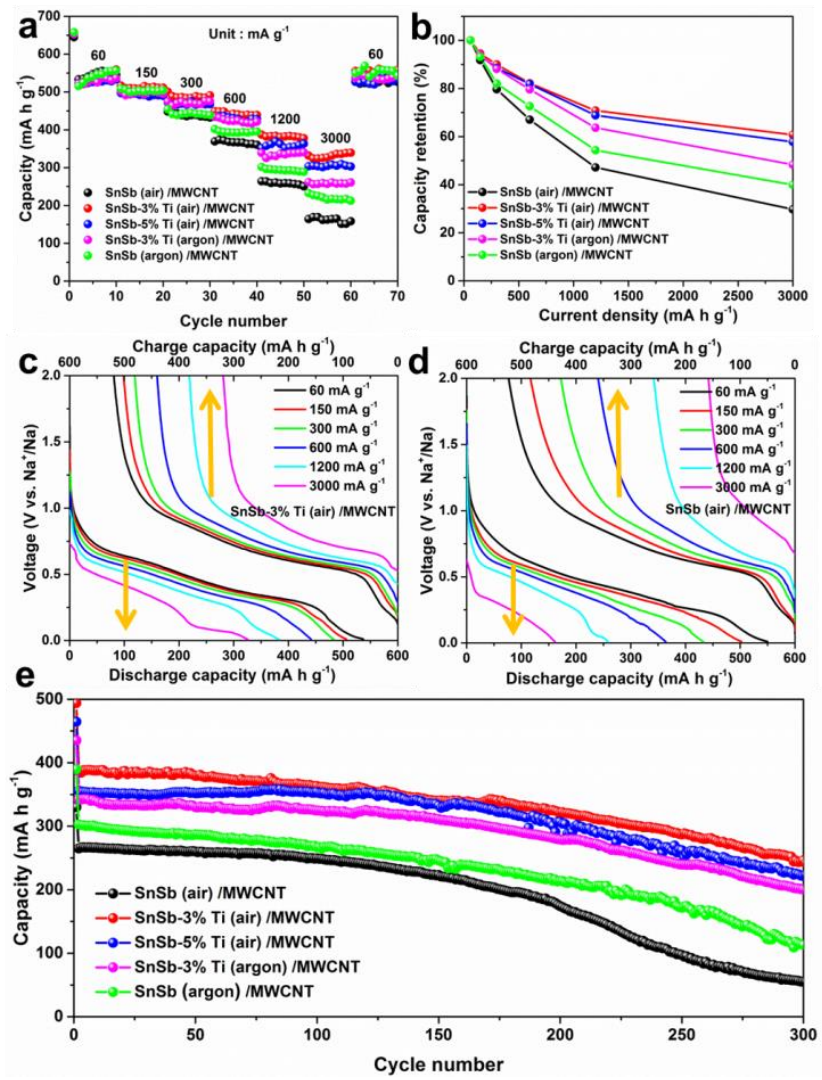

Figure 3. Electrochemical performance of SIBs. (a) Rate capabilities and (b) capacity retention of cells at various current densities. Galvanostatic discharge and charge profiles of (c) SnSb-3\% Ti (air) and (d) SnSb (air) electrodes at different current densities. (e) Long-term cycling tests of the cells at the current density of $1.2 \mathrm{~A} \mathrm{~g}^{-1}$. 
The rate performance was investigated at various current densities in the range of 60 to $3000 \mathrm{~mA}$ $\mathrm{g}^{-1}$. Figures $3 \mathrm{a}$ and $3 \mathrm{~b}$ show that the $\mathrm{SnSb}-3 \% \mathrm{Ti}$ (air) electrode exhibits the best rate performance among all the compared electrodes. It delivered 538, 509, 484, 442, 381, and 327 $\mathrm{mA} \mathrm{h} \mathrm{g}{ }^{-1}$ at the current densities of $60,150,300,600,1200$, and $3000 \mathrm{~mA} \mathrm{~g}^{-1}$, respectively, and had the highest capacity retention of $60.8 \%$ at $3 \mathrm{~A} \mathrm{~g}^{-1}$. In order to further investigate the effect of $\mathrm{TiO}_{2}$ formed during ball-milling, we employed $\mathrm{SnSb}-3 \% \mathrm{Ti}$ (argon) electrode, in which less $\mathrm{TiO}_{2}$ can be formed due to limited oxygen source only from functional group of MWCNTs not from air. It can be found that the capacity of the $\mathrm{SnSb}-3 \% \mathrm{Ti}$ (argon) electrode maintained $48.3 \%$ at 3 $\mathrm{A} \mathrm{g}^{-1}$, which is lower than that of the $\mathrm{SnSb}-3 \% \mathrm{Ti}$ (air) electrode. Both of the $\mathrm{SnSb}-3 \% \mathrm{Ti}$ (air) and $\mathrm{SnSb}-3 \% \mathrm{Ti}$ (argon) electrodes can sustain the electrical conductivity due to the reduction of the functional group of CNTs. However, the $3 \% \mathrm{Ti}$ in the $\mathrm{SnSb}-3 \% \mathrm{Ti}$ (air) electrode, can also scavenge oxygen from air to form more $\mathrm{TiO}_{2}$ than that in the $\mathrm{SnSb}-3 \% \mathrm{Ti}$ (argon) electrode, demonstrating that $\mathrm{TiO}_{2}$ formed enhanced the rate capability for the electrodes, due to the higher ion conductivity.

In addition, the $\mathrm{SnSb}$ (argon) electrode exhibits better rate performance compared to the $\mathrm{SnSb}$ (air) electrode. The $\mathrm{SnSb}$ (argon) maintains $216 \mathrm{~mA} \mathrm{~h} \mathrm{~g}^{-1}$ at $3 \mathrm{~A} \mathrm{~g}^{-1}$ with a capacity retention of $39.9 \%$ compared with that at $60 \mathrm{~mA} \mathrm{~g}^{-1}$, while the $\mathrm{SnSb}$ (air) electrode has a relatively lower capacity retention of $29.7 \%$ at $3 \mathrm{~A} \mathrm{~g}^{-1}$, which may be ascribed to the partial oxidation of the MWCNTs during the ball-milling process, where the generation of numerous $\mathrm{C}-\mathrm{O}$ and $\mathrm{C}=\mathrm{O}$ bonds on the carbon nanotubes (CNTs) decreases the electrical conductivity. The $\mathrm{SnSb}-5 \% \mathrm{Ti}$ (air) and $\mathrm{SnSb}-3 \% \mathrm{Ti}$ (argon) electrodes show slightly reduced capacities. Even with a similar amount of $\mathrm{TiO}_{2}$, the reduced capacity in $\mathrm{SnSb}-5 \% \mathrm{Ti}$ (air) is believed to be due to the excess of unreacted Ti and less SnSb active materials. 
On comparing the discharge-charge profiles of the $\mathrm{SnSb}$ (air) and $\mathrm{SnSb}-3 \% \mathrm{Ti}$ (air) electrodes at different current densities (Figures $3 \mathrm{c}$ and $3 \mathrm{~d}$ ), it was found that the latter showed significantly lower polarization than the former. The discharge-charge potential difference for the $\mathrm{SnSb}-3 \% \mathrm{Ti}$ (air) electrode changed very slightly with increasing current density. In contrast, for the $\mathrm{SnSb}$ (air) electrode, the discharge-charge potential difference was boosted significantly with increasing current density, indicating a higher polarization in the SnSb (air) electrode. The enlarged polarization of the $\mathrm{SnSb}$ (air) is mainly ascribed to the sluggish diffusion dynamics due to the lack of $\mathrm{TiO}_{2}$ phase and the oxidation of the MWCNTs. Electrochemical impedance spectroscopy measurements (Figure $\mathrm{S} 7$ ) show $\mathrm{SnSb}-3 \% \mathrm{Ti}$ (air) electrode has a lower chargetransfer and electrode resistances than those of $\mathrm{SnSb}$ (air).

The SnSb-3\% Ti (air) electrode also shows excellent long-term cycling stability (Figure 3e). Except for the initial low coulombic efficiency due to the formation of the solid electrolyte interphase layer, the coulombic efficiency remains above $99 \%$ for all electrodes in the first 300 cycles (Figure S8), indicating good reversibility during cycling. After 300 cycles, the SnSb-3\% $\mathrm{Ti}$ (air) electrode maintains the capacity of $246 \mathrm{~mA} \mathrm{~h} \mathrm{~g}^{-1}$, which represents reversible capacity of $63.7 \%$. In contrast, the capacity of the $\mathrm{SnSb}$ (air) electrode drops quickly to $55 \mathrm{~mA} \mathrm{~h} \mathrm{~g}^{-1}$ after 150 cycles, corresponding to $21.1 \%$ capacity retention with a large capacity fading of $0.263 \%$ per cycle. Furthermore, $\mathrm{TiO}_{2}$ could effectively assist the transport of ion even after 100 cycles (Figures S10 and S11). It is believed that the electrochemical performance could be further improved via electrode and electrolyte optimization for industrial application. 


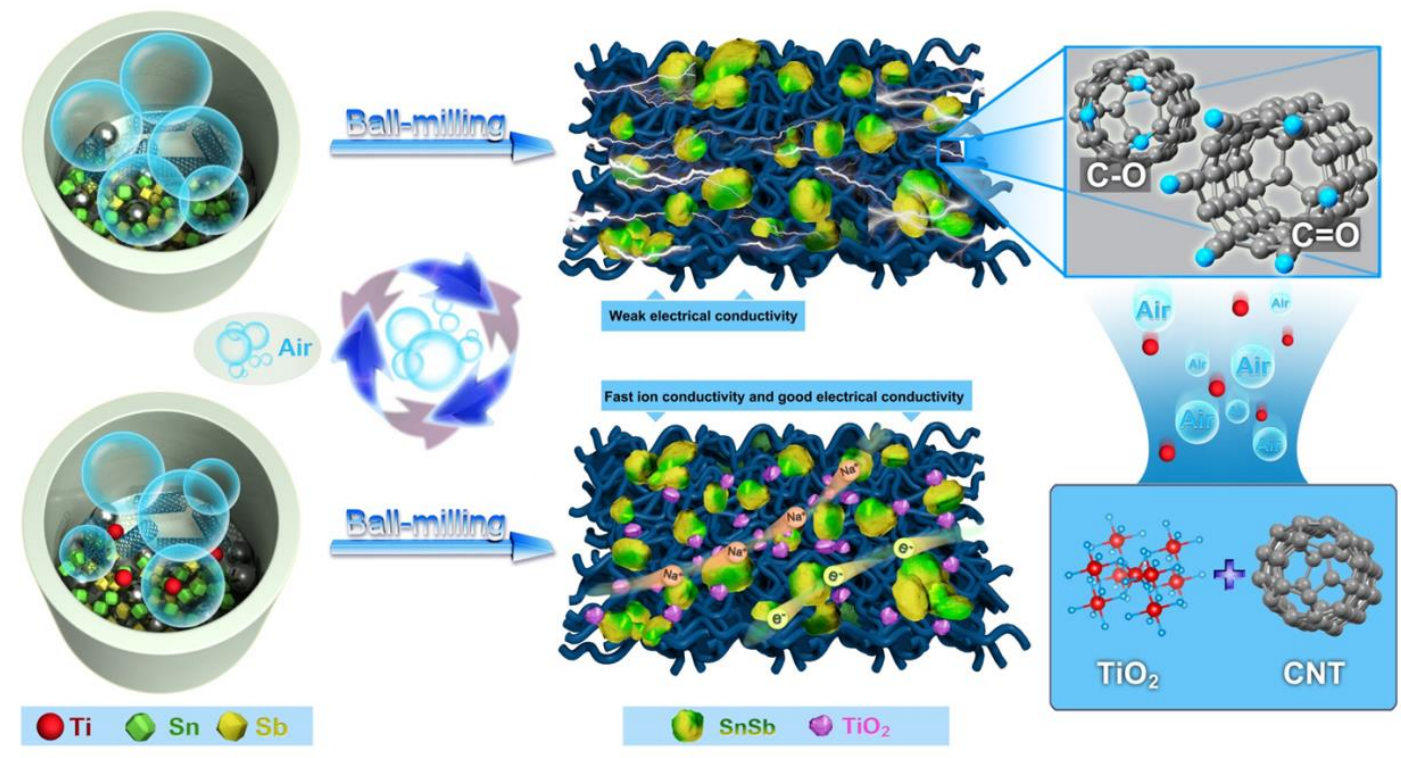

Scheme 1. Schematic illustration of the one-step preparation process and the enhanced electrochemical performance mechanism.

Scheme 1 illustrates the one-step and scalable method for electrode materials: During the ballmilling process in air, the oxygen will be preferentially captured by $\mathrm{Ti}$ and form $\mathrm{TiO}_{2}$, which is distributed uniformly in the active materials and carbon matrix. It appears that $3 \%$ Ti will be sufficient to take out all the oxygen in the chamber and some oxygen from the function groups on the CNT edges. Consequently, Ti prevents oxidation of the active alloy elements and reduces the oxidation of $\mathrm{CNT}$, thus maintaining the electrical conductivity of the $\mathrm{SnSb}$ composite electrode. During cycling, the $\mathrm{TiO}_{2}$ provides fast ionic conductivity, while the CNT acts as a good electrical conductor and buffering matrix to accommodate volume changes and synergistically maintain the charge transfer and the structural integrity. The cyclic voltammetry measurements at various scanning rates (Figures S12 and S13) confirm the Na diffusivity in the Ti-containing electrodes are notably higher than those of the other electrodes. In particular, the $\mathrm{SnSb}-3 \% \mathrm{Ti}$ (air) electrode shows a superior rate capability compared with the other ball-milled alloy-based electrodes reported in the literature (Figure S14). To obtain detailed insight into the 
high diffusion coefficient, we studied the process of $\mathrm{Na}$ ion migration in $\mathrm{TiO}_{2}$ by $\mathrm{DFT}$ calculations (Figure S15). Na ions can either diffuse in the channel along the $c$-direction (path A) or move to the neighbouring channel along the [110] direction (path B). The energy barriers calculated by the nudged elastic band (NEB) method are $0.23 \mathrm{eV}$ and $1.2 \mathrm{eV}$ for paths A and B, respectively. The lower diffusion barrier for path $\mathrm{A}$ indicates that $\mathrm{Na}$ ion migration in rutile $\mathrm{TiO}_{2}$ involves one-dimensional diffusion along the $c$-direction. At room temperature $(300 \mathrm{~K})$, the diffusion coefficient is $10^{-7} \mathrm{~cm}^{2} \mathrm{~s}^{-1}$, representing a significantly higher diffusion coefficient than those in other anodes (Table S2). Therefore, $\mathrm{TiO}_{2}$ component promotes Na diffusivity in the composite electrode and significantly improves the electrochemical performance of the $\mathrm{SnSb}$ electrode. Figure S16 shows the $\mathrm{SnSb}$ (air) sample has the lowest electrical conductivity among all samples. SnSb-3\% Ti (air), SnSb-5\% Ti (air) and $\mathrm{SnSb-3 \%}$ Ti (argon) powders have the higher electrical conductivity than the powders without Ti additive.

\section{Conclusions}

In summary, for the first time we have utilized the concept of an oxygen getter and designed a strategy which not only simplifies the ball milling process, but also enhances the electrochemical performance of alloy-based anodes. Owing to the merits of the strong oxygen affinity of Ti and the fast ionic conductivity of $\mathrm{TiO}_{2}$, this method could be promising for emerging applications of ball milling in energy storage. It is expected that our findings will provide new avenues for the improvements of ball-milling techniques and pave the way to reducing the costs for preparing large-scale electrode materials under air for industrial applications down to a practical level. 


\section{Supporting Information.}

Additional details on synthesis, characterization, computational calculations, electrochemical measurements, Raman spectra, simulated NPD results, thermodynamic calculations, XPS analysis, STEM results of cycled electrode, diffusion coefficient tests and calculations, additional electrochemical measurements.

\section{Conflicts of interest}

There are no conflicts to declare

\section{Corresponding Author}

*E-mail: zguo@uow.edu.au

\section{ACKNOWLEDGMENT}

The authors are grateful to operational staff, especially Prof. Vanessa Peterson, at ANSTO, Australia, for supporting on NPD collection, Prof. Yuanzhen Chen at Xi'an Jiaotong University for XPS characterization. The authors thank Dr. Tania Silver for critical reading of the manuscript. Financial support provided by the Australian Research Council (FT150100109, FT160100251, and DP170102406) is gratefully acknowledged. Wenchao Zhang would like to thank the UOW for providing scholarships.

\section{References}


1. Larcher, D.; Tarascon, J.-M. Nat. chem. 2015, 7, 19-29.

2. Zhu, H.; Zheng, J.; Chen, Y.; Weadock, N,; Wan, J,; Vaaland, O,; Han, X,; Li, T,; Hu. L. Nano letters 13, 2013, 7, 3093-3100.

3. Lu, J.; Chen, Z.; Ma, Z.; Pan, F.; Curtiss, L. A.; Amine, K.; Nat. Nanotech. 2016, 11, 1031-1038.

4. Zheng, Y.; Zhou, T.; Zhao, X.; Pang, W. K.; Gao, H.; Li, S.; Zhou, Z.; Liu, H.; Guo, Z. Adv. Mater. 2017, 26, 29.

5. Deng, X.; Wei, Z.; Cui, C.; Liu, Q.; Wang, C.; Ma, J. J. Mater. Chem. A. 2018, 6, 4013-4022.

6. Liang, J.; Gao, X.; Guo, J.; Chen, C.; Fan, K.; Ma, J. Science China Materials. 2018, $61,30-38$

7. He, H.; Gan, Q.; Wang, H.; Xu, G.; Zhang, X.; Huang, D.; Fu, F.; Tang, Y.; Amine, K.; Shao, M. Nano Energy, 2018, 44, 217-227.

8. Wang, Q.; Zhang, W.; Guo, C.; Liu, Y.; Wang, C.; Guo, Z. Advanced Functional Materials, 2017, 27, 1703390.

9. He, H.; Huang, D.; Pang, W.; Sun, D.; Wang, Q.; Tang, Y.; Ji, X.; Guo, Z.; Wang, H. Adv. Mater, 2018, DOI: 10.1002/adma.20181013.

10. Mao, J.; Cui, C.; Wu, M.; Zhang, M.; Gao, T.; Fan, X.; Chen, J.; Wang, T.; Ma, J.; Wang, C. Nano Energy 2018, 45, 346-352.

11. Qian, J.; Wu, X.; Cao, Y.; Ai, X.; Yang, H. Angew. Chem. Int. Ed. 2013, 125, 47314734.

12. Liu, Z.; Yu, X.-Y.; Lou, X. W. D.; Paik, U. Energy Environ. Sci. 2016, 9, 2314-2318. 
13. Sun, J.; Lee, H.-W.; Pasta, M.; Yuan, H.; Zheng, G.; Sun, Y.; Li, Y.; Cui, Y. Nat. Nanotech. 2015, 10, 980-985.

14. Zhang, W.; Mao, J.; Pang, W. K.; Guo, Z.; Chen, Z. Electrochimica Acta, 2017, 235, 107-113.

15. Liu, B.; Chen, H. M.; Liu, C.; Andrews, S. C.; Hahn, C.; Yang, P. J. Am. Chem. Soc. 2013, 135, 9995-9998.

16. Yu, D.; Goh, K.; Wang, H.; Wei, L.; Jiang, W.; Zhang, Q.; Dai, L.; Chen, Y. Nat. Nanotech. 2014, 9, 555-562.

17. Odziomek, M.; Chaput, F.; Rutkowska, A.; Świerczek, K.; Olszewska, D.; Sitarz, M.; Lerouge, F.; Parola, S. Nat. Commun. 2017, 8, 15636.

18. Xiao, L.; Cao, Y.; Xiao, J.; Wang, W.; Kovarik, L.; Nie, Z.; Liu, J. Chem. Commun. 2012, 48, 3321-3323;

19. Zhang, W.; Mao, J.; Li, S.; Chen, Z.; Guo, Z. J. Am. Chem. Soc. 2017, 139, 33163319.

20. Zhang, B.; Dugas, R.; Rousse, G.; Rozier, P.; Abakumov, A. M.; Tarascon, J.-M. Nat. Commun. 2016, 7.

21. Stout, V. L.; Gibbons, M. D. J. Appl. Phys. 1955, 26, 1488-1492.

22. Mao, C.; Tan, M.; Zhang, L.; Wu, D.; Bai, W.; Liu, L. Calphad 2018, 60, 81-89.

23. Su, D.; Dou, S.; Wang, G. Chem. Mater. 2015, 27, 6022-6029;

24. Ji, L.; Gu, M.; Shao, Y.; Li, X.; Engelhard, M. H.; Arey, B. W.; Wang, W.; Nie, Z.; Xiao, J.; Wang, C. Adv. Mater. 2014, 26, 2901-2908.

25. Kim, Y. J.; Shin, T. S.; Do Choi, H.; Kwon, J. H.; Chung, Y.-C; Yoon, H. G. Carbon $\mathbf{2 0 0 5}, 43,23-30$. 
26. Wang, J.; Polleux, J.; Lim, J.; Dunn, B. J. Phys. Chem. C 2007, 111, 14925-14931.

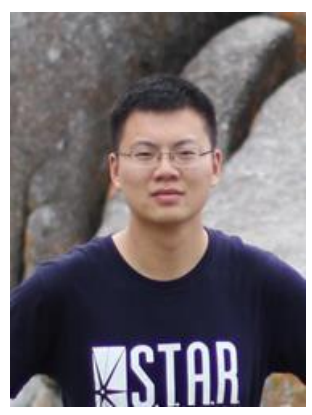

Wenchao Zhang earned his B.S. and Master degrees in Materials Science and Engineering at the Central South University, PR China in 2012 and 2015, respectively. He is currently a Ph.D. candidate under the supervision of Prof. Zaiping Guo at the School of Mechanical, Materials, Mechatronics and Biomedical Engineering, University of Wollongong, Australia. His current research interests focus on the design and application of alloy-based anode materials for metalion batteries.

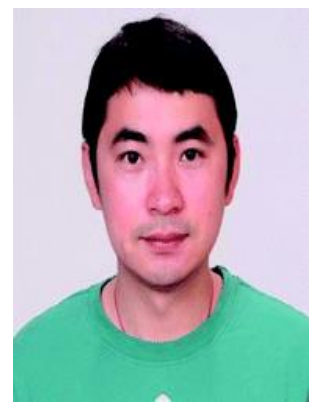

Jianfeng Mao received his Ph.D. in materials science from the University of Wollongong, Australia, in 2012. After working at the Max-Planck-Institute für Kohlenforschung, University of Glasgow and University of Maryland, he moved back to the University of Wollongong in 2015. His research interests are in inorganic materials for rechargeable batteries, catalysis, and hydrogen storage.

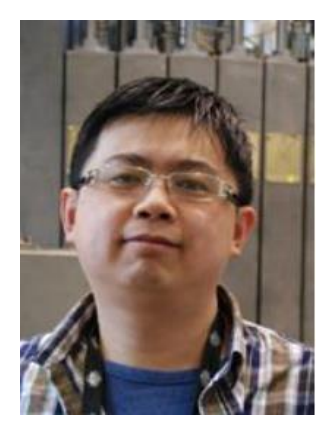

Wei Kong Pang received his Ph.D. in Applied Physics from Curtin University, Western Australia in 2011. After completion, he was first appointed as a postdoctoral research fellow in the Department of Chemistry at the National Taiwan University and the Department of Materials 
Engineering at Tatung University, Taiwan. In 2013 he joined the University of Wollongong and the Australian Nuclear Science and Technology Organisation as a postdoctoral research fellow. Recently he was awarded an Australian Research Council (ARC) Future Fellowship and is currently a senior research fellow at the Institute for Superconducting and Electronic Materials (ISEM), University of Wollongong.

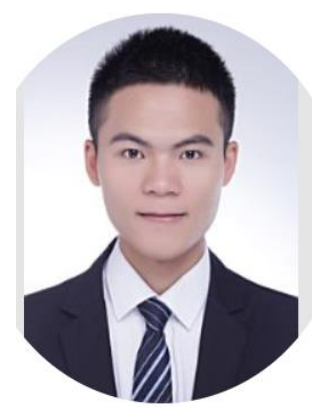

Xing Wang earned his B.S. and Master degrees in Materials Science and Engineering at the Central South University, PR China in 2012 and 2015, respectively. He is currently a Ph.D. candidate at the Institute for Chemical \& Bioengineering in Zurich (ETHZ). His current research interests focus on the First-principles calculations, nanoscale simulation, heterogeneous catalysis and phase stability and phase transformations.

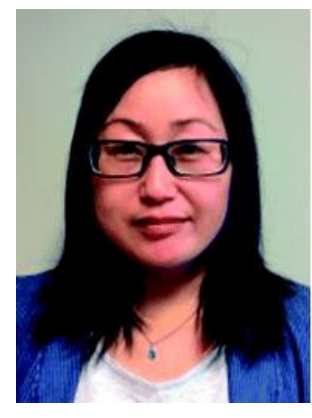

Guo Zaiping obtained her Ph.D. from the University of Wollongong in 2003. After her postdoctoral research with Prof. Huakun Liu at the Institute for Superconducting and Electronic Materials (ISEM), University of Wollongong, she joined the Faculty of Engineering in 2008. She is currently a senior professor and ARC Queen Elizabeth II (QEII) Fellow in the School of Mechanical, Materials \& Mechatronic Engineering and the Institute for Superconducting \& Electronic Materials, University of Wollongong. Her work is focused on practical applications of various nanomaterials as electrode materials for energy storage or conversion technologies, including rechargeable batteries, hydrogen storage, and supercapacitors. 
Creating fast ion conducting composites via in-situ introduction of Titanium as oxygen getter

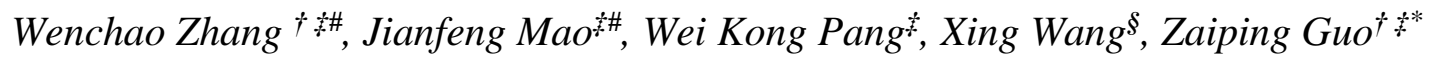

$\dagger$ School of Mechanical, Materials, Mechatronics \& Biomedical Engineering, Faculty of Engineering and Information Sciences, University of Wollongong, NSW 2500, Australia.

¥nstitute for Superconducting \& Electronic Materials, University of Wollongong, Wollongong, NSW, 2522, Australia.

$\S$ Institute for Chemical \& Bioengineering, ETH Zurich, Vladimir Prelog Weg 1, 8093 Zurich, Switzerland

*E-mail:zguo@uow.edu.au

\# These authors contributed equally to this work 


\section{Methods}

\section{Synthesis of electrode materials}

$\mathrm{SnSb}-x \% \mathrm{Ti}$ (air or argon) powders were synthesised by a facile one-step approach. In a typical ball-milling procedure, elemental Sn (Sigma-Aldrich, $\geq 99.8 \%$ ), Sb (Sigma-Aldrich, $\geq 99.8 \%$ ) and multi-wall carbon nanotubes (MWCNTs) were used without further purification as the raw materials in the weight ratio of $\mathrm{Sn}: \mathrm{Sb}$ : MWCNTs = 43.2: 44.3: 12.5 (with $\mathrm{Sn}$ and $\mathrm{Sb}$ in the molar ratio of 1:1, respectively). The ball-milling was conducted in a planetary QM-1SP2 ball mill for $30 \mathrm{~h}$, and the elemental mixture was milled at $500 \mathrm{rpm}$ using stainless steel balls $10 \mathrm{~mm}$ in diameter with a powder-to-ball weight ratio of 1:30. All sample storage and handling took place under air atmosphere. SnSb (air) powders were prepared without the addition of Ti. By adding 3\% Ti or 5\% Ti (Sigma-Aldrich, $\geq 99.8 \%$ ) powders in situ into the ball-milling jar, SnSb3\% $\mathrm{Ti}$ (air) and $\mathrm{SnSb}-5 \% \mathrm{Ti}$ (air) powders were prepared to optimize the proper ratio of Ti. For comparison purposes, $\mathrm{SnSb}$ (argon) and $\mathrm{SnSb}-3 \% \mathrm{Ti}$ (argon) powders were prepared in an argon filled glove box (MBraun Unilab).

The volume of the ball-milling vial we used is $100 \mathrm{~mL}$. The approximately oxygen content can be calculated as $100 \mathrm{~mL} * 21 \%$ (volume of oxygen in air) $=21 \mathrm{~mL}(\sim 0.028 \mathrm{~g})$. Based on the equation $\left(\mathrm{Ti}+\mathrm{O}_{2}=\mathrm{TiO}_{2}\right), 0.03 \mathrm{~g} \mathrm{O}_{2}$ could be consumed by $\sim 0.042 \mathrm{~g} \mathrm{Ti}$, which is corresponding to $\sim 2.7$ wt. \% in the total amount $(0.648 \mathrm{~g} \mathrm{Sn}+0.665 \mathrm{~g} \mathrm{Sb}+0.187 \mathrm{~g}$ carbon nanotubes $)$ of the powder. Besides, the extra $\mathrm{Ti}$ will react with partial $\mathrm{C}-\mathrm{O}$ and $\mathrm{C}=\mathrm{O}$ bonds existed on muti-wall carbon 
nanotubes (MWCNTs). Therefore, the total amount for removing the entire $\mathrm{O}$ during ball-milling is around $3 \%$.

The electrical conductivity was measured by means of a static DC method using an Ozawa Rz2001i. The resultant fine powders were densified by a cold isostatic pressing (CIP) instrument under an axial compressive stress of $60 \mathrm{MPa}$ for $5 \mathrm{~min}$. The obtained highly dense pellets were cut and polished into rectangular bars with dimensions of $\sim 6 * 2 * 2 \mathrm{~mm}^{3}$, and then annealed for 12 $\mathrm{h}$ at $300{ }^{\circ} \mathrm{C}$. The measurement of the electrical conductivity was conducted on an Ozawa RZ2001i (Japan) instrument under helium atmosphere at 323K.

\section{Characterization}

The crystal structures of the as-prepared powders were characterized by powder X-ray diffraction (XRD, Rigaku D/max 2500) with a $\mathrm{Cu} \mathrm{K \alpha}$ source $(\lambda=1.54056 \AA)$ at a scanning rate of $8^{\circ} \min ^{-1}$. Raman spectra were collected on a JobinYvon HR800 Raman spectrometer. Highresolution neutron powder diffraction (NPD) data of the as-prepared SnSb sample were collected using the high-resolution neutron powder diffractometer, namely, ECHIDNA ${ }^{1}$, at the Open Pool Australian Light-water (OPAL) research reactor at the Australian Nuclear Science and Technology Organization (ANSTO). The as-prepared SnSb-3\% Ti (air) was loaded into a 9-mm vanadium can, and the neutron beam wavelength used was 1.6219(2) $\AA$, which was confirmed using the $\mathrm{La}^{11} \mathrm{~B}_{6}$ National Institute of Standards and Technology (NIST, USA) standard reference material (SRM) 660b. NPD data were recorded for the $2 \theta$ range from 6.5 to $164^{\circ}$ with a step size of $0.125^{\circ}$. X-ray photoelectron spectroscopy (XPS) was conducted onan AXIS ultra DLD. The morphology of the synthesized powders was characterized on a JEOL JSM-7500FA field-emission scanning electron microscope (FESEM) and on a transmission electron 
microscope (TEM, JEOL 2010F). The elemental mapping and EELS spectra were collected with a scanning TEM (STEM, ARM-200F).

\section{Computational details}

DFT calculations were performed by using the Quickstep module implemented in the CP2K program $^{2}$ with the Perdew-Burke-Ernzerhof (PBE) functional ${ }^{3}$ and Geodecker-Teter-Hutter (GTH) pseudopotentials ${ }^{4}$. The double-zeta valence plus polarization (DZVP) basis set was employed $^{5}$. Brillouin zone integration was performed at the gamma point. An energy cut-off of $800 \mathrm{Ry}$ and the convergence criterion of $10^{-7}$ Ha were used for all calculations. The nudged elastic band method (NEB) ${ }^{6}$ implemented in $\mathrm{CP} 2 \mathrm{~K}$ was used to calculate the diffusion energy barriers. Fifteen images were used for each NEB calculation. The calculated lattice constants for rutile $\mathrm{TiO}_{2}$ (Space group number 136) are $a=b=4.62 \AA$ and $c=2.98 \AA$, which are in good agreement with the experimental values $a=b=4.60 \AA, c=2.98 \AA$. The possible sites for Na ions in the $\mathrm{TiO}_{2}$ structure are the octahedral sites $(0.5,0,0)$ and $(0,0.5,0)$. Supercells consisting of $2 a \times 2 b \times 3 c$ unit cells containing 24 formula units $\left(\mathrm{TiO}_{2}\right)$ were used. After one $\mathrm{Na}$ wad added, the length of the $a$ - and $b$-axis parameters changed from $4.62 \AA$ to $4.72 \AA$ and $4.76 \AA$,

respectively, while the $c$-axis parameter decreased from $2.98 \AA$ to $2.97 \AA$. Under the assumption that the local diffusion of $\mathrm{Na}$ ions does not perturb the shape of the overall crystal structure, those new lattice constants were used in the NEB calculations, with full relaxation of the internal coordinates.

In this paper, the enthalpy of formation per oxygen atom was calculated as follows:

$$
\Delta H_{f}=\frac{E_{C N T+n O}-E_{C N T}-n E_{O}}{n}
$$


where $E_{\mathrm{CNT}+\mathrm{O}}, E_{\mathrm{CNT}}$, and $E_{\mathrm{O}}$ are the calculated electronic energies of CNT-O compound, CNT, and an $\mathrm{O}$ atom, respectively.

The diffusion coefficient can be calculated from the energy barriers along the diffusion path using transition state theory. The diffusion coefficient can be written as:

$$
D=\Gamma d^{2}
$$

where $\Gamma$ is the rate of jumping to a neighbouring site and $d$ is the diffusion distance. This jumping rate can be written as:

$$
\Gamma=v e^{-\Delta E / k_{b} T}
$$

Where $\Delta E$ is the diffusion energy barrier, $k_{\mathrm{b}}$ is Boltzmann's constant, $T$ is the absolute temperature, and $v$ is the effective frequency associated with atomic vibration, which can be assumed to be a constant, $1 \times 10^{13} \mathrm{~Hz}^{7}$.

The Gibbs free energy and enthalpy of selected phases in the Sn-O, Sb-O, and Ti-O binary systems were calculated using Thermal-Calc software ${ }^{8}$. For a binary system, $\Delta G_{\mathrm{m}}$ (where $\Delta G_{\mathrm{m}}$ represents the nucleation driving force of the crystallization process) of $\Phi$ phase could be calculated by Equation (1):

$$
\Delta G_{m}=x_{A}^{\emptyset} \bar{G}_{A}^{L}+x_{B}^{\emptyset} \bar{G}_{B}^{L}-G^{\varnothing}
$$

where $x_{A}^{\emptyset}, x_{B}^{\emptyset}$ are the mole fractions of A and B in $\Phi$ phase, $G^{\varnothing}$ is the Gibbs free energy of $\Phi$ phase. $\bar{G}_{A}^{L}$ and $\bar{G}_{B}^{L}$ are the Gibbs free energy values of $\mathrm{A}$ and $\mathrm{B}$ in the liquid state. The enthalpy, $\Delta H_{\mathrm{m}}$, could be calculated in a similar way. 


\section{Electrochemical measurements}

The working electrodes were fabricated using a slurry-coating method. The synthesized materials were mixed with Super P carbon black and carboxymethyl cellulose (CMC) in the weight ratio of $8: 1: 1$, respectively. Deionized (DI) water was used as the dispersing agent. Then, the slurry was coated on copper foil and dried in a vacuum oven at $80{ }^{\circ} \mathrm{C}$ overnight, followed by pressing at $300 \mathrm{~kg} \mathrm{~cm}^{-2}$. Coin-type (CR2032) cells were assembled in an argon-filled glove box with oxygen and water content lower than $0.1 \mathrm{ppm}$. Na half-cells were assembled with sodium metal as the counter electrode, glass fibre as separator, and $1 \mathrm{M} \mathrm{NaClO}_{4}$ in propylene carbonate (PC) with $5 \%$ fluoroethylene carbonate (FEC) additive as electrolyte. The mass loading of active material (SnSb- $x \% \mathrm{Ti}$ ) was over $0.99 \mathrm{mg} \mathrm{cm}{ }^{-2}$, corresponding to a total mass loading of $1.41 \mathrm{mg} \mathrm{cm}^{-2}$. Cyclic voltammetry (CV) and electrochemical impedance spectroscopy (EIS) tests were conducted on a VMP-3 electrochemical workstation. The cells were galvanostatically chargeddischarged between 0.01 and $2.0 \mathrm{~V}$ versus $\mathrm{Na} / \mathrm{Na}^{+}$at various current densities on Neware battery test systems. The specific capacity was calculated based on the weight of SnSb-x\% Ti. 


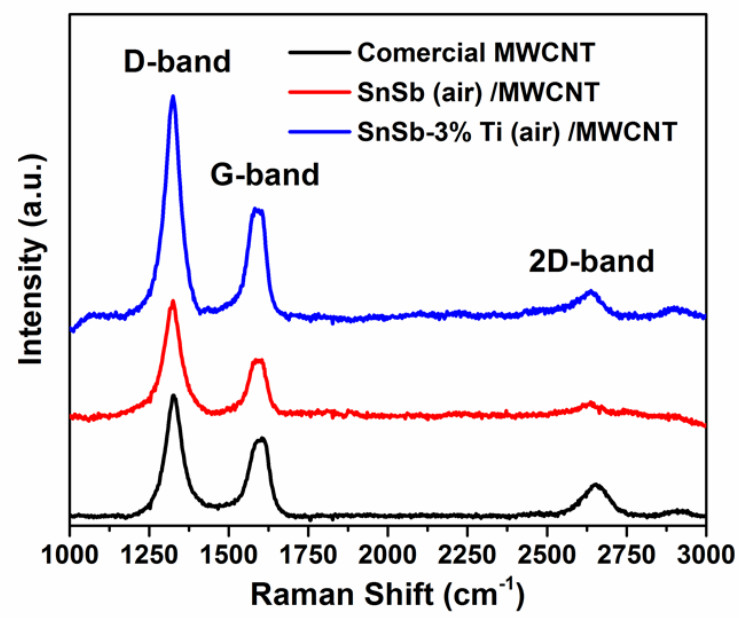

Figure S1. Raman spectra of the as-prepared powders. 


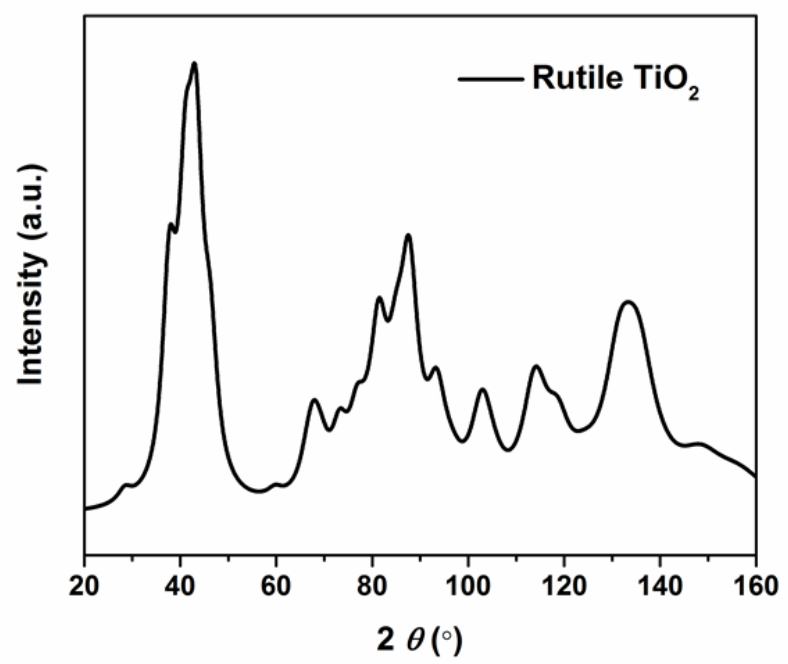

Figure S2. Simulated NPD results for rutile $\mathrm{TiO}_{2}$. 

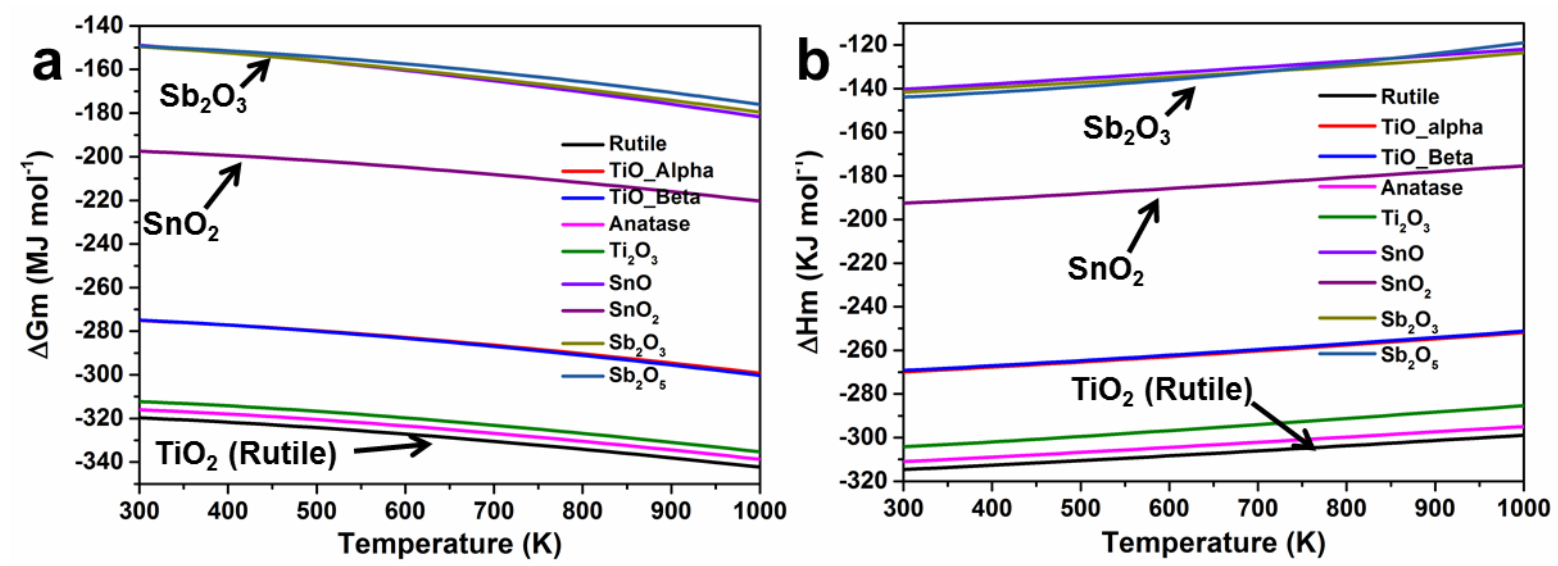

Figure S3. Thermodynamic calculations of the selected phases in the Ti-O, Sn-O, and $\mathrm{Sb}-\mathrm{O}$ systems. (a) Gibbs free energy calculations; (b) enthalpy formation energy calculations.

The Gibbs formation energies of titanium oxides, Sn oxides, and Sb oxides were calculated and the results are given in Figure S3, where rutile $\mathrm{TiO}_{2}$ exhibits the lowest Gibbs formation energy and the lowest formation enthalpy among all three polymorphs of titanium oxide (anatase, brookite, and rutile), suggesting that rutile $\mathrm{TiO}_{2}$ is the most stable binary compound in the Ti-O system. The calculated results also show that $\mathrm{Ti}$ has a stronger oxygen affinity than $\mathrm{Sn}$ and $\mathrm{Sb}$ with increasing temperature, which is consistent with the DFT calculation results above. 

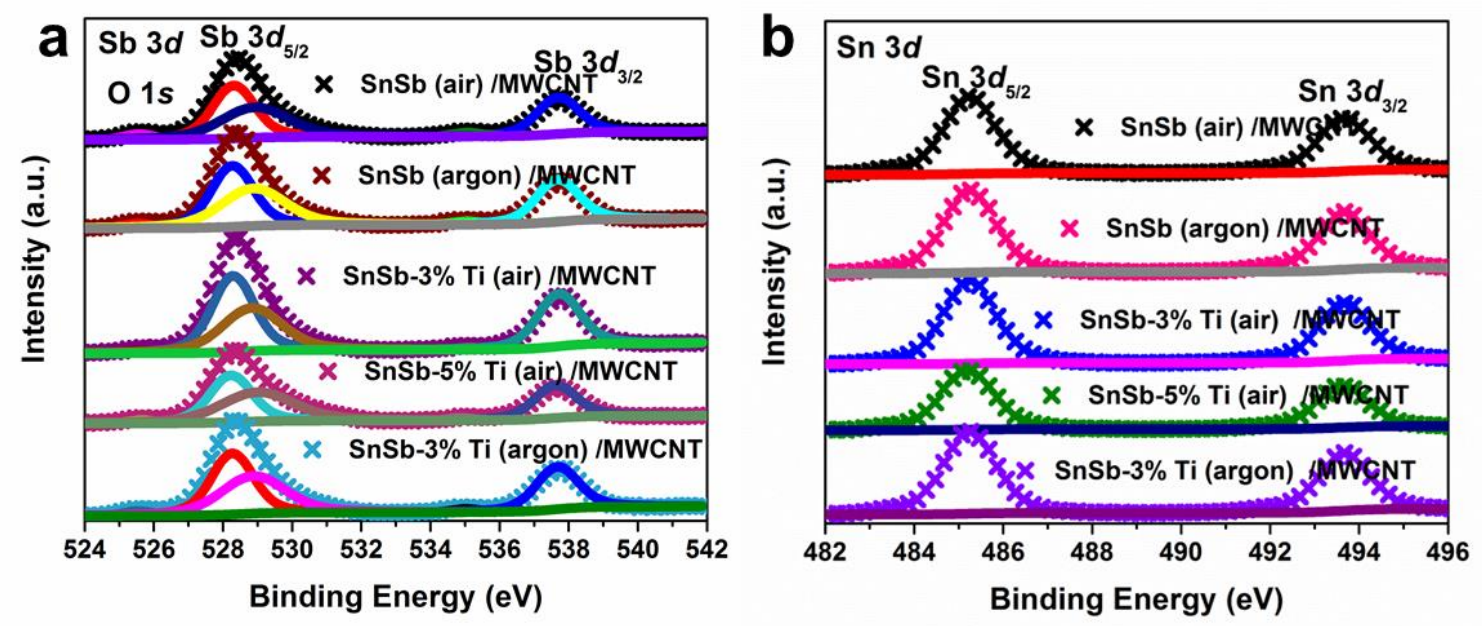

Figure S4. XPS analysis of the as-prepared samples. (a) Sb 3d and O 1s peaks; (b) Sn 3d peaks. 

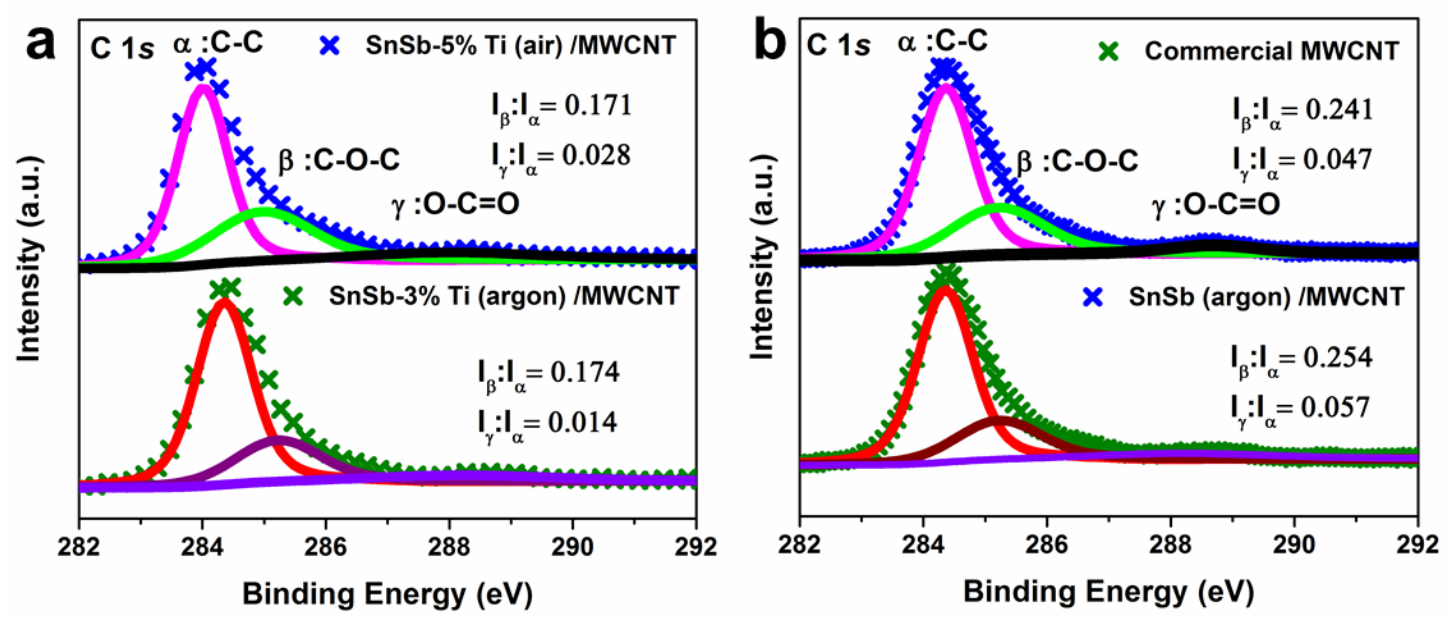

Figure S5. C $1 s$ XPS analysis of the as-prepared samples. (a) SnSb-5\% Ti (air) and SnSb-3\% Ti (argon) samples; (b) commercial MWCNTs and SnSb (argon) samples. 

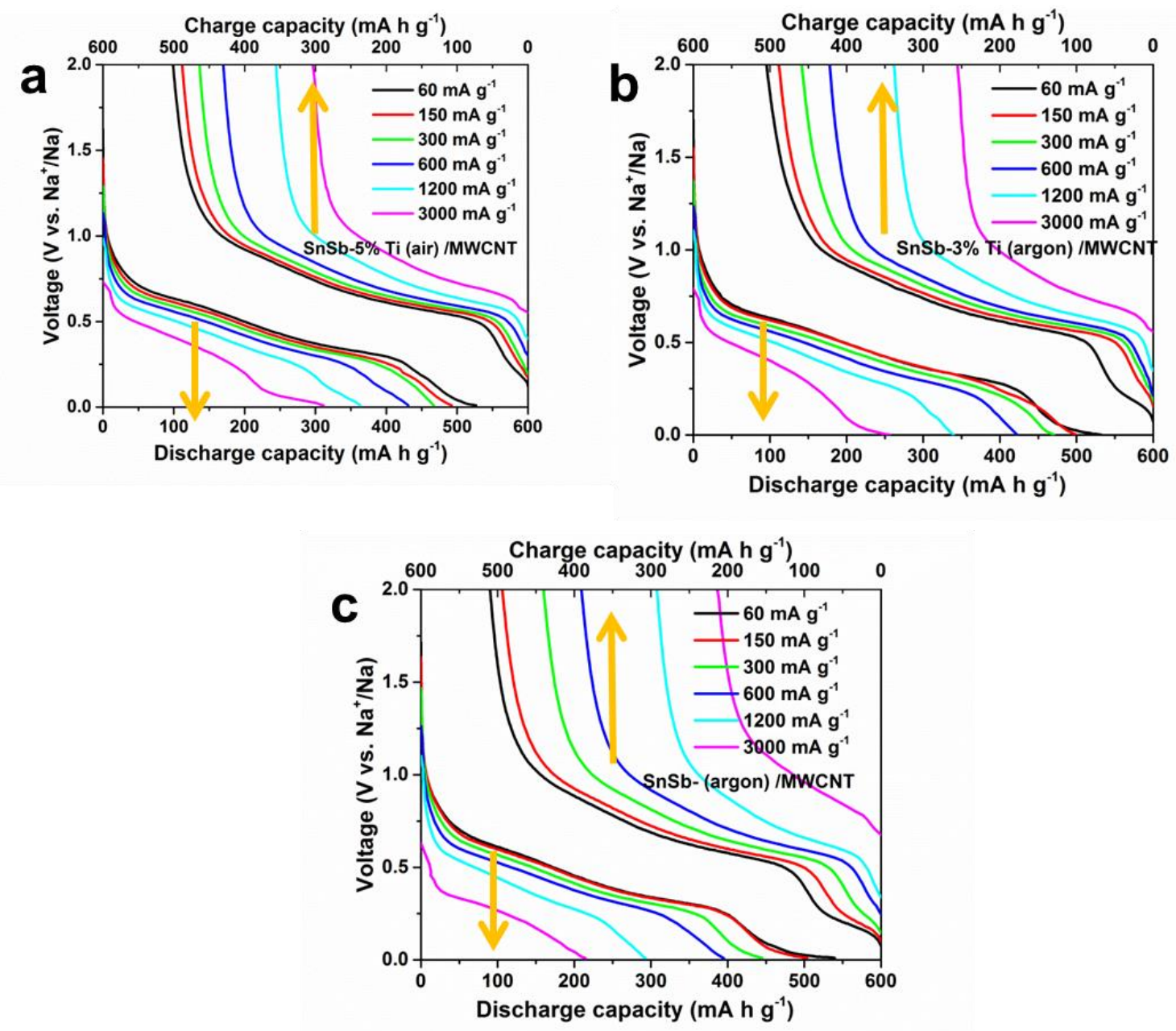

Figure S6. Galvanostatic discharge-charge profiles of a) $\mathrm{SnSb-5 \%} \mathrm{Ti}$ (air), b) $\mathrm{SnSb}-3 \% \mathrm{Ti}$ (argon), and c) $\mathrm{SnSb}$ (argon) electrodes at different current densities in the range of 60 to $3000 \mathrm{~mA} \mathrm{~g}^{-1}$. 


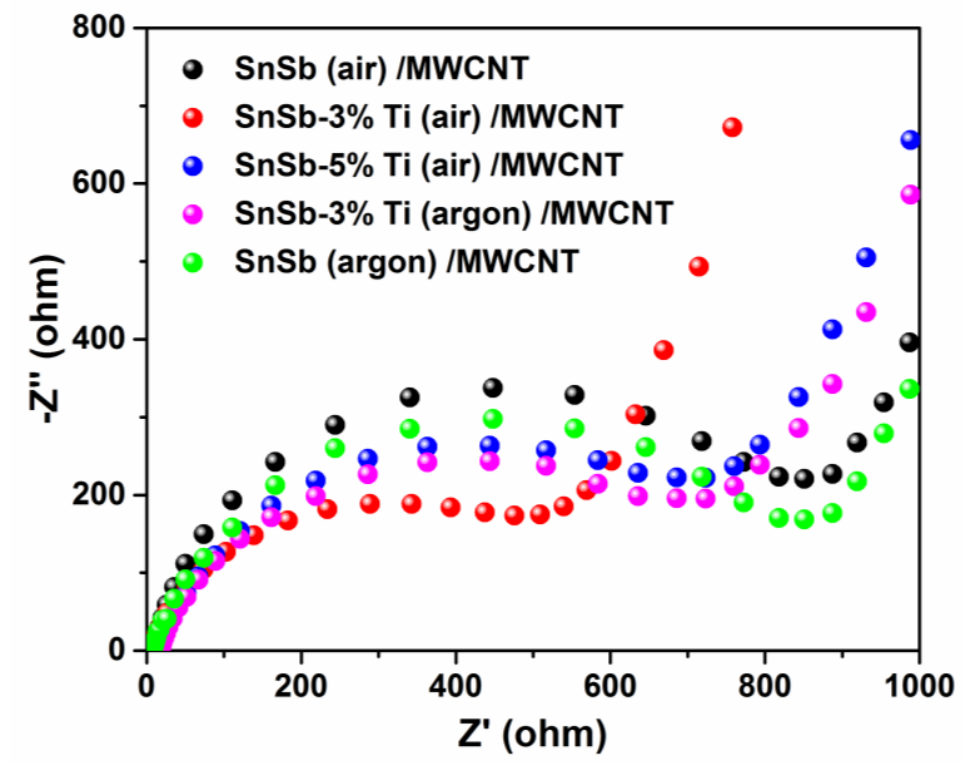

Figure S7. Electrochemical impedance spectroscopy comparison of all the electrodes before cycling.

Electrochemical impedance spectroscopy (EIS) measurements were also performed to evaluate all the electrodes. As shown in Figure S7, the high-frequency semicircle of the SnSb-3\% Ti (air) cell is clearly the smallest among all the cells, suggesting that the $\mathrm{SnSb}-3 \% \mathrm{Ti}$ (air) electrode has a lower charge-transfer resistance. 


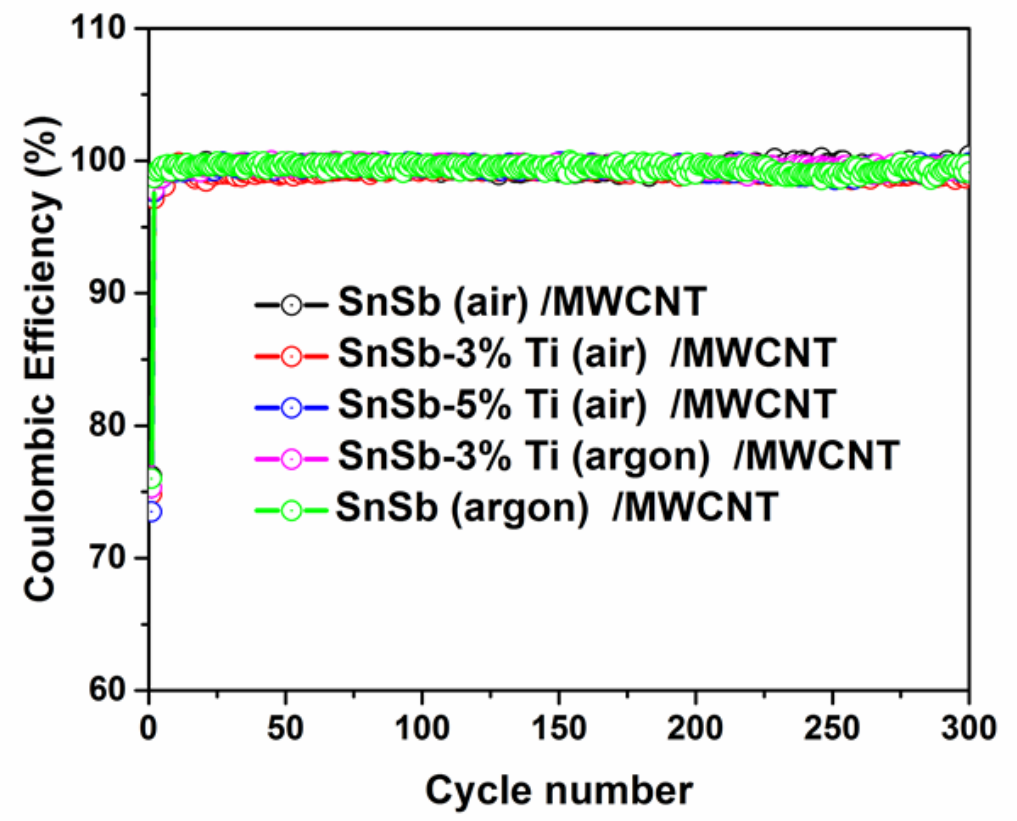

Figure S8. Coulombic efficiency comparison of the as-prepared electrodes. 


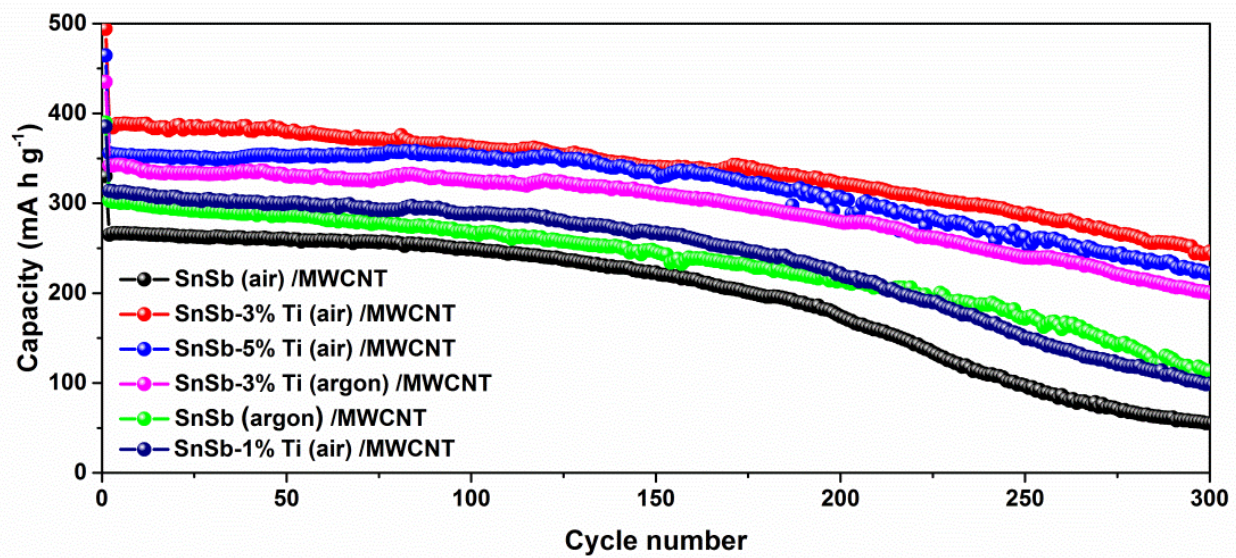

Figure S9. Long-term cycling tests of the cells at the current density of $1.2 \mathrm{~A} \mathrm{~g}^{-1}$.

The $\mathrm{SnSb}-1 \% \mathrm{Ti}$ (air) electrode show a slighter higher capacity and better cycling performance than that in the $\mathrm{SnSb}$ (air) electrode at $1.2 \mathrm{~A} \mathrm{~g}^{-1}$, which is possibly due to the less amount of $\mathrm{TiO}_{2}$ formed during ball-milling. 1\% Ti can only partially scavenge the oxygen in the ball-milling jar, indicating the ion conductivity and electrical conductivity could not be improved significantly. 


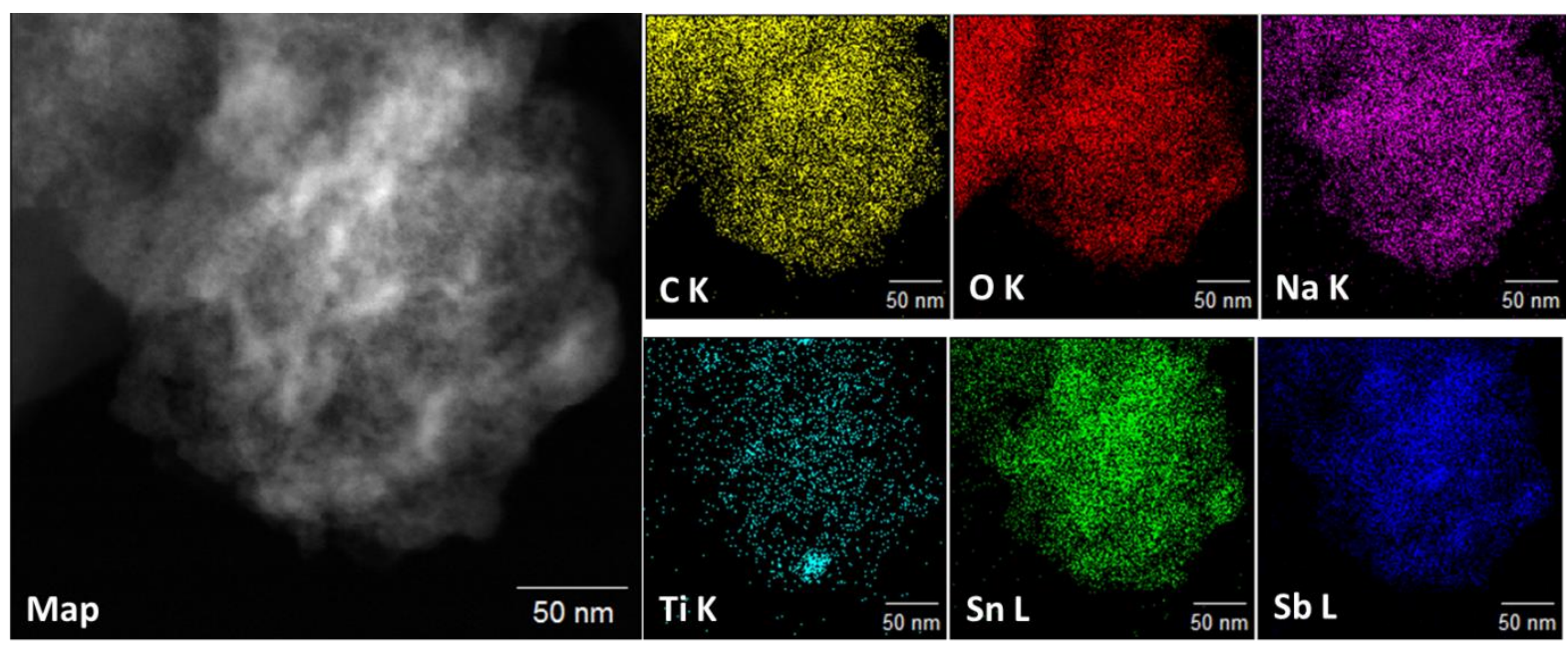

Figure S10. STEM-mapping of SnSb-3\% Ti (air) electrode after 100 cycles. 

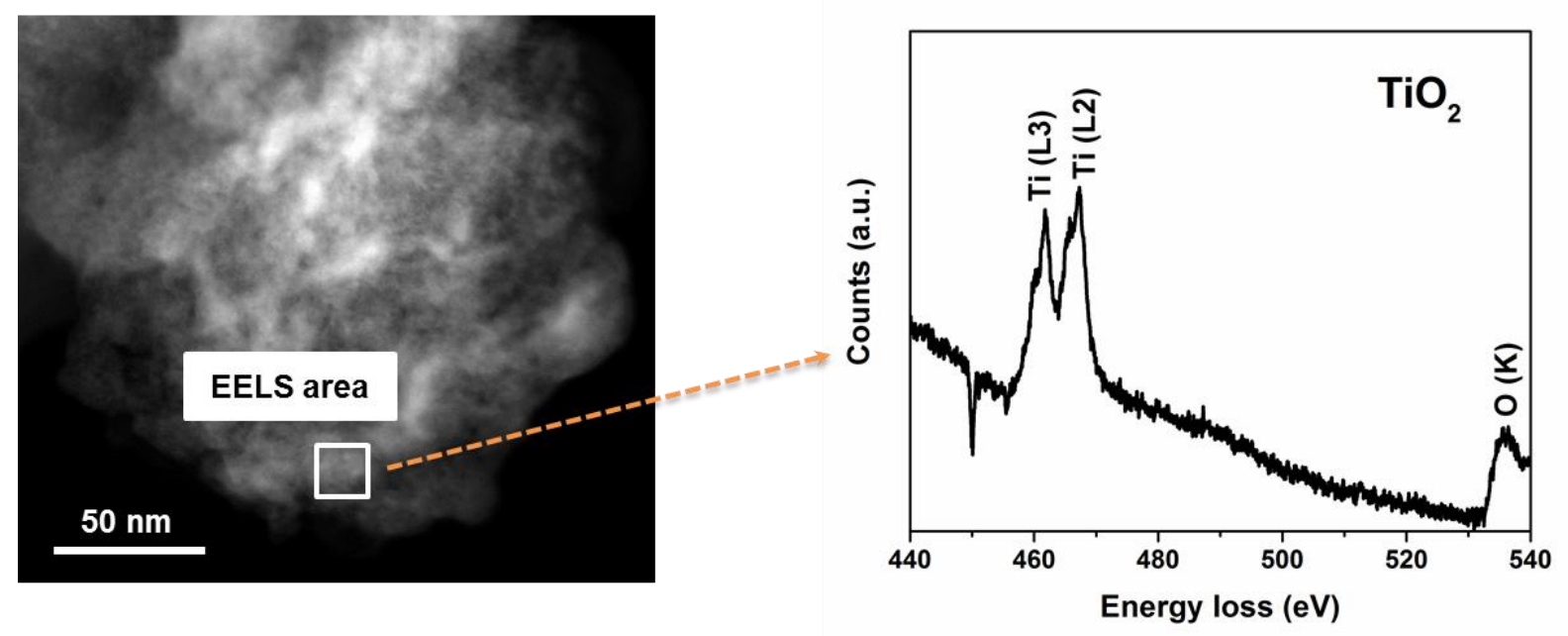

Figure S11. STEM image (left) and EELS spectrum (right) for the selected area of SnSb3\% Ti (air) electrode after 100 cycles.

X-ray mapping and EELS were carried out to identify the Ti-containing phase in the SnSb-3\% Ti (air) electrode after 100 cycles, as shown in Figures S10 and S11. The fine structure near theTiL3, Ti-L2, and O-K edges matches that of rutile $\mathrm{TiO}_{2}$. This suggests that the rutile $\mathrm{TiO}_{2}$ is stable and capable of effectively assisting the transport of ions even after 100 cycles. 

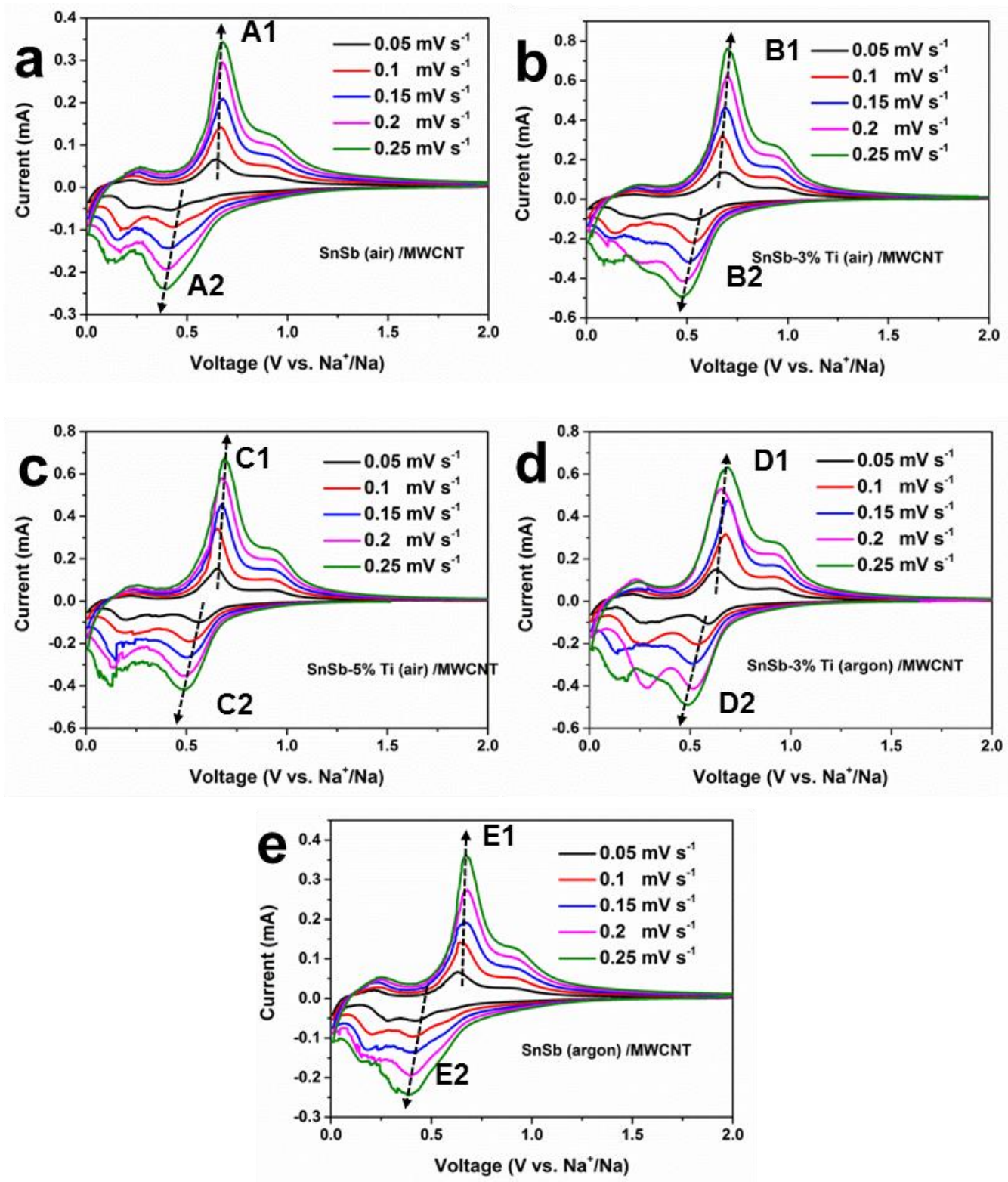

Figure S12. CV curves at different scan rates. (a) SnSb (air); (b) SnSb-3\% Ti (air); (c) SnSb5\% Ti (air); (d) SnSb-3\% Ti (argon); and (e) SnSb (argon) electrodes. 

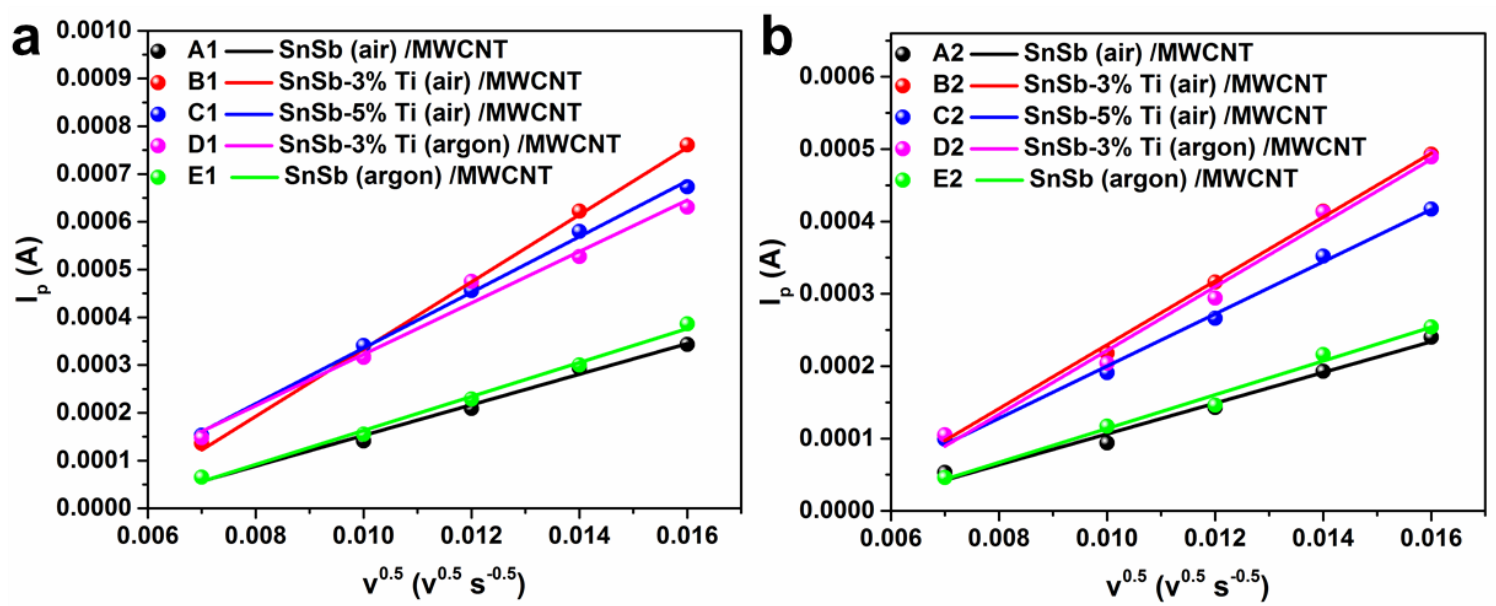

Figure S13. Peak currents versus $v^{0.5}\left(v^{0.5} \cdot s^{-0.5}\right)$, where $v$ is the scan rate and $s$ the time, and the corresponding linear fits. (a) The cathodic reaction adopted from A1-E1; (b) the anodic reaction adopted from A2-E2.

The average sodium-ion diffusion coefficient $\left(D_{\mathrm{Na}^{+}}{ }^{+}\right)$can be calculated based on the RandlesSevcik equation:

$$
i_{p}=0.4463 n F \sqrt{\frac{n F D}{R T} A C \sqrt{v}}
$$

Where $i_{p}$ represents the peak current, $n$ is the number of electrons, $F$ is the Faraday constant, $R$ is the gas constant, $T$ is the temperature, $A$ is the surface area of the electrode, $D$ is the diffusion coefficient, $C$ stands for the concentration of sodium-ions in the electrolyte, and $v$ is the voltage scanning rate. 


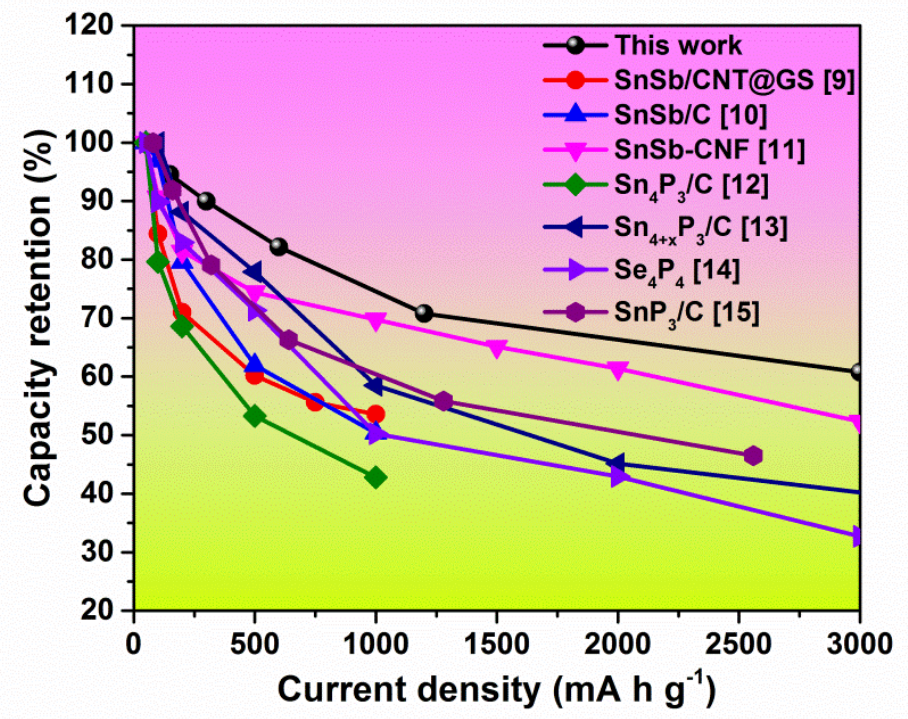

Figure S14. Comparison of capacity retention of $\mathrm{SnSb-3 \%} \mathrm{Ti}$ (air) electrode in this work with SnSb composites prepared by other methods and other alloy-based anodes synthesised by ball-milling methods $9,10,11,12,13,14,15$. 
a

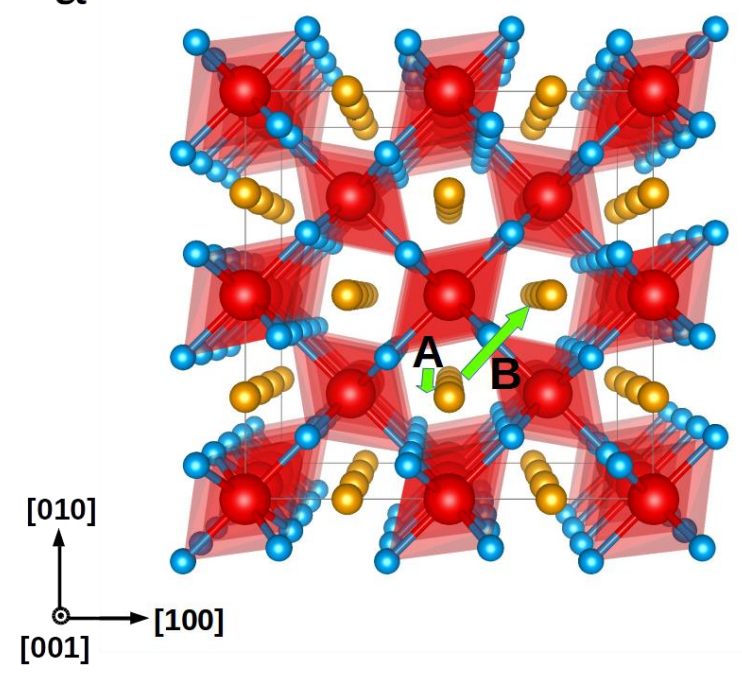

b

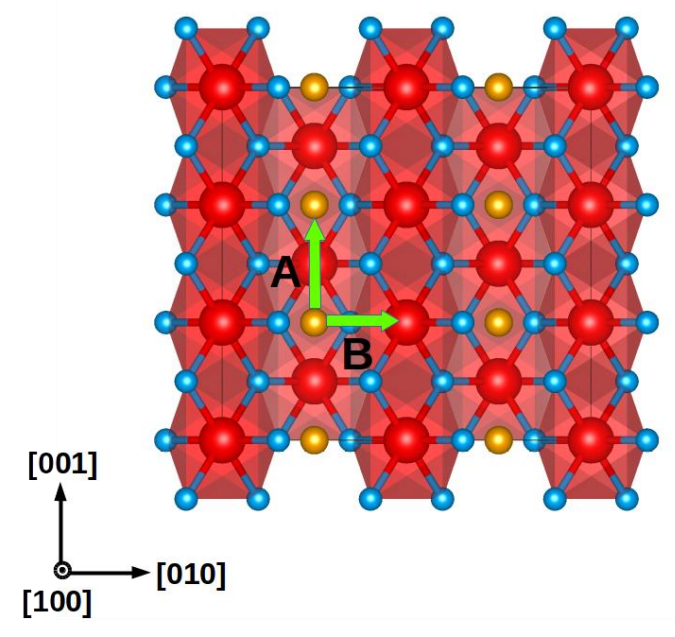

Figure S15. Na diffusion pathways in (a) $c$-axis view and (b) $a$-axis view. Path A represents the diffusion of $\mathrm{Na}$ along a channels parallel to the $c$-direction. Path $\mathrm{B}$ represents diffusion of $\mathrm{Na}$ to the next channel along the [110] direction. Ti: red; O: blue; Na: orange; $\mathrm{TiO}_{6}$ octahedra: red. 


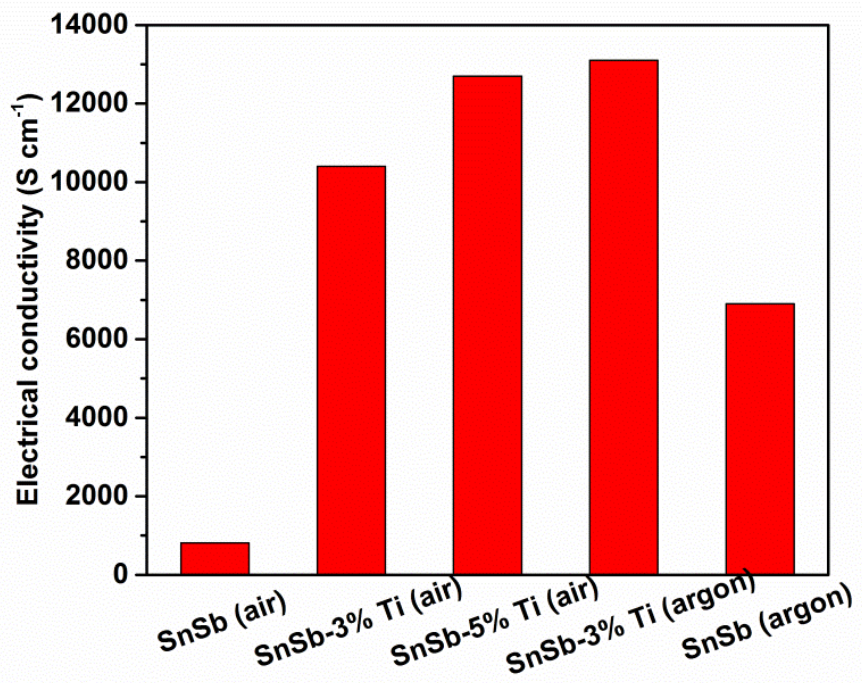

Figure S16. The electrical conductivity comparison of the as-prepared powders

Figure S16 shows the SnSb (air) sample has the lowest electrical conductivity among all samples. SnSb-3\% Ti (air), SnSb-5\% Ti (air) and SnSb-3\% Ti (argon) powders have the higher electrical conductivity than the powders without Ti additive.

Besides, $\mathrm{SnSb}-3 \% \mathrm{Ti}$ (air) powder has a lower electrical conductivity than $\mathrm{SnSb}-3 \% \mathrm{Ti}$ (argon) and $\mathrm{SnSb}-5 \% \mathrm{Ti}$ (air) powders, however, the $\mathrm{SnSb}-3 \% \mathrm{Ti}$ (air) electrode shows the best rate capability, further demonstrating that the introduction of Ti oxygen getter not only helps sustain the electrical conductivity, but also forming $\mathrm{TiO}_{2}$ which facilitate sodium ion diffusion to some extent, and enhance the rate capability. 


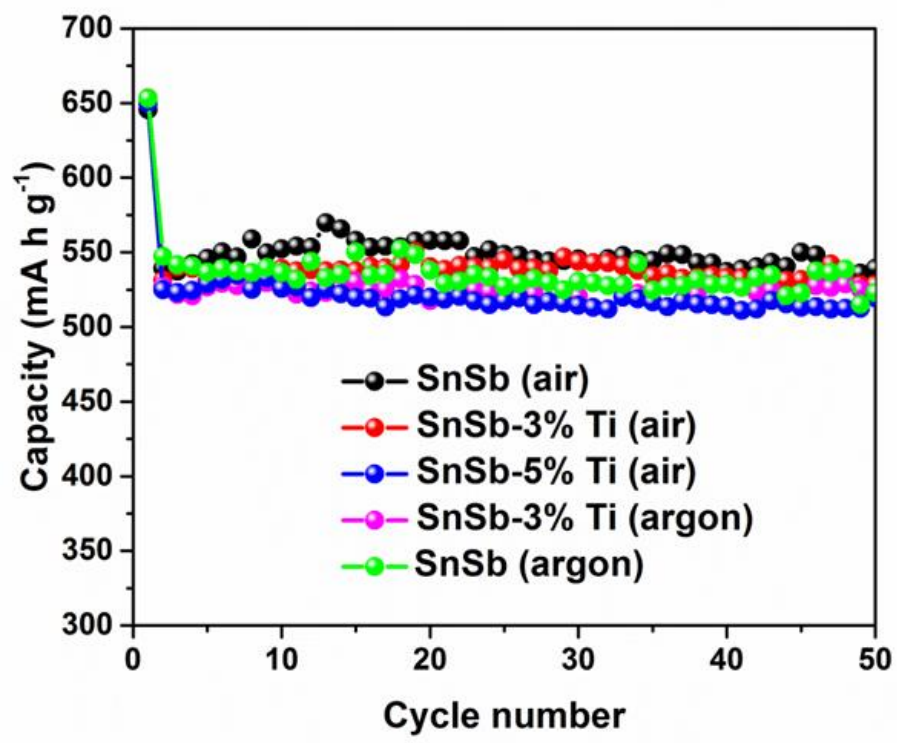

Figure S17. The Cycling performance of the as-prepared electrodes at $60 \mathrm{~mA}^{-1}$.

All the as-prepared electrodes have high reversible capacities over $520 \mathrm{~mA} \mathrm{~h} \mathrm{~g}^{-1}$ at $60 \mathrm{~mA} \mathrm{~g}^{-1}$. After we carefully compared the capacities of the various electrodes, the $\mathrm{SnSb}$ (air) electrode exhibited a slightly higher specific capacity than the other electrodes around $550 \mathrm{~mA} \mathrm{~h} \mathrm{~g} \mathrm{~g}^{-1}$ at 60 $\mathrm{mA} \mathrm{g}^{-1}$. 


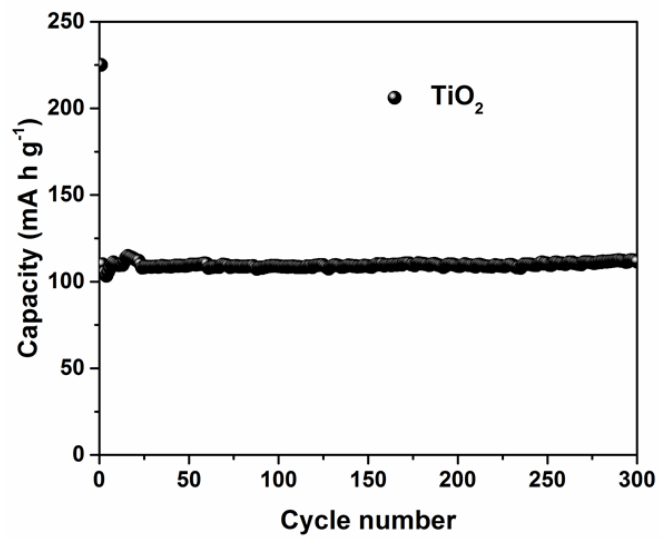

Figure S18. The Cycling performance of the $\mathrm{TiO}_{2}$ electrode at $60 \mathrm{~mA} \mathrm{~g}^{-1}$.

The $\mathrm{TiO}_{2}$ electrode maintained a reversible capacity of around $110 \mathrm{~mA} \mathrm{~h} \mathrm{~g}$ at $60 \mathrm{~mA} \mathrm{~g}^{-1}$. In this work, $3 \mathrm{wt}$ \% $\% \mathrm{Ti}$ has been added to scavenge oxygen from the air and the $\mathrm{C}-\mathrm{O}$ or $\mathrm{C}=\mathrm{O}$ groups to form $\mathrm{TiO}_{2}$, indicating that the content of $\mathrm{TiO}_{2}$ would be no more than $3 \mathrm{wt} . \%$. Therefore, the capacity contribution from $\mathrm{TiO}_{2}$ itself would be lower than $3.3 \mathrm{~mA} \mathrm{~h} \mathrm{~g}^{-1}$, which can be ignored.

Although the capacity contribution from $\mathrm{TiO}_{2}$ is negligible, $\mathrm{TiO}_{2}$ can enhance the rate capability of the electrodes due to its high ionic conductivity. In addition, the Ti can also scavenge oxygen from air to sustain the electrical conductivity (avoiding the oxidation of CNTs). Hence, the rate capability of the electrodes containing $\mathrm{TiO}_{2}$ is still higher than for those without $\mathrm{TiO}_{2}$, especially at high current rate. 
Table S1. Crystallography of SnSb determined from Rietveld analysis of high-resolution NPD spectrum.

\begin{tabular}{ccccccc}
\hline \multicolumn{7}{c}{ SnSb (space group = R-3m ) } \\
$\mathbf{a = b = 4 . 3 4 5 ( 5 )} \AA, \mathbf{c}=\mathbf{5 . 2 8 5 ( 3 )} \AA$ \\
\hline Atom & $\begin{array}{c}\text { Wyckoff } \\
\text { site }\end{array}$ & $\mathrm{x}$ & $\mathrm{y}$ & $\mathrm{z}$ & Uiso & Occupancy \\
Sb & $6 \mathrm{c}$ & 0 & 0 & $0.49(2)^{*}$ & $0.013(2)^{* *}$ & $0.5 \sim$ \\
Sn & 6c & 0 & 0 & $0.49(2)^{*}$ & $0.013(2)^{* *}$ & $0.5 \sim$ \\
\hline
\end{tabular}

$*$ *** constrained to be same. $\sim$ fixed. 
Table S2. Diffusion coefficient comparison with other anode materials.

\begin{tabular}{|c|c|c|c|}
\hline Electrode materials & $\begin{array}{c}\text { Lithium or } \\
\text { sodium ion } \\
\text { batteries } \\
\text { (LIBs or } \\
\text { SIBs) }\end{array}$ & $\begin{array}{c}\text { Diffusion } \\
\text { coefficient } \\
\left(\mathrm{cm}^{2} \mathrm{~s}^{-1}\right)\end{array}$ \\
\hline Rutile $\mathrm{TiO}_{2}$ & SIBs & $10^{-7}$ & Reference \\
\hline $\mathrm{Sn}$ & LIBs & $1.8 \times 10^{-11}$ & 16 \\
\hline $\mathrm{Sb}$ & LIBs & $1.1 \times 10^{-11}$ & 17 \\
\hline $\mathrm{SnSb}$ & LIBs & $4 \times 10^{-12}$ & 17 \\
\hline $\mathrm{graphite}$ & LIBs & $1.12 \times 10^{-10}$ & 19 \\
\hline $\mathrm{Si}$ & LIBs & $5.1 \times 10^{-12}$ & 20 \\
\hline $\mathrm{CoP}$ & SIBs & $\sim 3 \times 10^{-13}$ & 21 \\
\hline $\mathrm{Ge}$ & SIBs & $\sim 10^{-13}$ & 22 \\
\hline $\mathrm{TiS} \mathrm{S}_{2}$ & $\mathrm{SIBs}$ & $\sim 10^{-12}$ & 19 \\
\hline & & & \\
\hline
\end{tabular}




\section{Supplementary References}

1. K.-D. Liss, B. Hunter, M. Hagen, T. Noakes, S. Kennedy, Physica B: Condensed Matter 2006, 385, 10101012.

2. J. VandeVondele, M. Krack, F. Mohamed, M. Parrinello, T. Chassaing, J. Hutter, Comput. Phys. Commun. 2005, 167, 103-128.

3. J. P. Perdew, K. Burke, M. Ernzerhof, Phy. Rev. Lett. 1996, 77, 3865.

4. S. Goedecker, M. Teter, J. Hutter, Phy. Rev. B 1996, 54, 1703.

5. B. G. Lippert, J. H. Parrinello, Michele, Mol. Phy. 1997, 92, 477-488.

6. G. Henkelman, B. P. Uberuaga, H. Jónsson, J. Chem. Phys. 2000, 113, 9901-9904.

7. K. Kang, D. Morgan, G. Ceder, Phy. Rev. B 2009, 79, 014305.

8. B. Sundman, B. Jansson, J.-O. Andersson, Calphad 1985, 9, 153-190.

9. Li L, Seng KH, Li D, Xia Y, Liu H, Guo Z. Nano Research 2014, 7, 1466.

10. Xiao L, Cao Y, Xiao J, Wang W, Kovarik L, Nie, Z, Liu J. Chem. Com. 2012, 48, 3321-3323.

11. Ji L, Gu M, Shao Y, Li X, Engelhard M, Arey B, Wang W, Nie Z, Xiao J, Wang C, Zhang J, Liu J. Adv. Mater. 2014, 26, 2901-2908.

12. Qian J, Xiong Y, Cao Y, Ai X, Yang H. Nano Lett. 2014, 14, 1865-1869.

13. Li W, Chou S, Wang J, Kim J, Liu H, Dou S. Adv. Mater. 2014, 26, 4037-4042 (2014).

14. Lu Y, Zhou P, Lei K, Zhao Q, Tao Z, Chen J. Adv. Energy Mater. 2017, 7, 7.

15. Fan X, Mao J, Zhu Y, Luo C, Suo L, Gao T, Han F, Liou S, Wang C. Adv. Energy Mater. 2015, 5, 18. 
16. Xie J, Song W, Zheng Y, Liu S, Zhu T, Cao G, Zhao X. International Journal of Smart and Nano Materials 2011, 2, 261-271.

17. Besenhard J, Wachtler M, Winter M, Andreaus R, Rom I, Sitte W. J. Power Sources 1999, 81, 268-272.

18. Yu P, Popov BN, Ritter JA, White RE. J. Electrochem. Soc. 1999, 146, 8-14.

19. Ding N, Xu J, Yao Y, Wegner G, Fang X, Chen C, Lieverwirth I. Solid State Ionics 2009, 180, 222-225.

20 Zhang K, Park M, Zhang J, Lee G-H, Shin J, Kang Y-M. Nano Research 2017, 1-14.

21. Abel, P. R., Lin, Y. M., de Souza, T., Chou, C. Y., Gupta, A., Goodenough, J. B., ... \& Mullins, C. B. J. Phys. Chem. C 2013, 117, 18885-18890.

22. Winn D, Shemilt J, Steele B. Mater. Res. Bull. 1976, 11, 559-566. 